\title{
Simbología de poder en Guayabo de Turrialba
}

\author{
Luis Hurtado de Mendoza* \\ Elena Troyo Vargas ${ }^{* *}$
}

\begin{abstract}
RESUMEN
Se examina el propósito simbólico de los conjuntos arquitectónicos del Monumento Nacional Guayabo de Turrialba, respecto del fenómeno de rango y poder sociopolítico en la antigua sociedad cacical de la cuenca media del Reventazón (200 a.C.-1300 d.C.). Se evalúa la historia cultural; cronología y estructura arquitectónica; volumen de las obras civiles y requerimientos de materiales constructivos y de fuerza de trabajo.
\end{abstract}

Palabras clave: Arqueología, Guayabo, Cacicazgos, Poder político, Diferenciación social

\section{ABSTRACT}

Inferences are made on the symbolic purpose of the architectonic compounds at the Guayabo de Turrialba National Monument, in regard to rank and sociopolitical power in the prehispanic chiefdom society of the Reventazón watershed (200 B.C.-A.D. 1300). Data analyses are performed on the cultural history, chronology of monumental architecture, size and volume of public works, and estimated requirements of labor and building materials.

Keywords: Archaeology, Guayabo, Chiefdoms, Political power, Social differentiation

La teoría antropológica de los cacicazgos puede ser consultada, en sus aspectos fundamentales, en los trabajos de Service (1971), Sahlins (1958) y Fried (1967). Una fuente importante de ejemplos etnográficos en el Área Intermedia es el "Handbook of South American Indians" compilado por Steward (1949). También existen dos estudios etnohistóricos muy útiles acerca de los cacicazgos de Costa Rica (Ibarra, 1984) y Panamá (Helms, 1979) y algunas aplicaciones prácticas de la teoría general, para intentar dilucidar problemas de investigación en la arqueología de Costa Rica (ejs. Snarskis, 1987; Hurtado de Mendoza, 1988, 2004; Hurtado de Mendoza y Gómez, 1985).

\footnotetext{
* Luis Hurtado de Mendoza. Peruano. Ph.D. Antropólogo Proyecto Hidroeléctrico Toro 3, Instituto Costarricense de Electricidad, lhurtadom@ice.go.cr

** Elena Troya Vargas. Costarricense. Licenciada en Antropología con énfasis en Arqueología. Centro de Investigación y Conservación del Patrimonio Cultural. Ministerio de Cultura y Juventud, San José.
} 
Por lo general, se ha hecho rutinaria la admisión de evidencia de cacicazgos cuando un depósito arqueológico produce rasgos arquitectónicos y tumbas elaboradas que contienen ofrendas funerarias que denotan "status". Así, no parece necesario fundamentar el término, propiamente, aunque tal vez sí su contenido conceptual. Para esto último, y pensando de primera intención en los propósitos de este trabajo, se revisan algunos de los trabajos arriba mencionados.

Para Elman R. Service (1971) un cacicazgo trasciende el nivel de una sociedad tribal cuando adopta dos aspectos importantes: 1) Es "usualmente" una sociedad más densa que la tribal, característica que implica mayor población en el mismo territorio, gracias a una productividad mayor; y 2) la sociedad se torna más compleja y organizada, lo cual se refleja en el surgimiento de "centros de coordinación" de las actividades económicas, sociales y religiosas. Una importante calificación de lo anterior, es expresada por Service (1971:133) en los siguientes términos:

Tanto la mayor productividad como la mayor densidad poblacional, que caracterizan a los cacicazgos, no se deben necesariamente a algún desarrollo tecnológico en particular, aunque hay casos en que tal cosa parece haber sucedido, pero en la mayoría de casos ha sido más importante alguna situación ambiental que resultó selectiva a favor de la especialización de la producción y de la redistribución de los productos a partir de un control central."

La especialización y la redistribución son dos condiciones muy importantes. En comparación con las bandas y tribus, en las cuales la especialización de la producción y la redistribución de los productos, son ocasionales, en los cacicazgos estas dos condiciones adquieren una dimensión social privilegiada. Dice Service (1971:134):

Los cacicazgos son sociedades redistributivas con una agencia central permanente de coordinación. Es más, la agencia central no solo tiene un rol económico, sino que asume funciones adicionales de índole social, política y religiosa. Una vez que es establecida esta agencia, actúa para estimular y preservar la integración de la sociedad por la integración misma.

Agrega Service (1971:134) que, conjuntamente, la especialización de la producción y la redistribución de los productos cumplen un rol fundamental como "base organizada para generar una sociedad integrada ... y más densa”.

Estas últimas citas son relevantes para el presente análisis. Señalan, de primera intención, tres funciones típicas de los cacicazgos que poseen visibilidad arqueológica: la especialización de la producción; la redistribución de los bienes; y la integración sociopolítica. En segundo término, indican la necesidad de una agencia central o centro desde donde se maneja la redistribución y se alienta la especialización, todo lo cual también tiene visibilidad arqueológica. Adicionalmente, sugieren que la agencia central y quienes la manejan, no se limita a administrar tangibilidades económicas, sino que asumen funciones adicionales en las que el simbolismo ideológico es importante. 
La redistribución, que alienta y depende de la integración de la sociedad, puede ser vista como una forma de intercambio local, asistido por la agencia central; pero en una dimensión más amplia, interregional, el intercambio de productos sofisticados (arqueológicamente visible) fomenta la especialización, otra de las condiciones características de la sociedad cacical. Al respecto, dice Service (1971:136):

El intercambio recíproco primitivo que se efectúa entre sociedades, nunca es un asunto que dependa de la iniciativa individual, si no que se trata de una actividad pública, o de interés grupal. Esto requiere de la organización de la producción para generar un excedente para el intercambio, por un lado, y recíprocamente, aquello que se recibe en el intercambio debe ser redistribuido entre la gente. Consecuentemente, la organización, que implica alguna forma de liderazgo, tiene que ver con los dos aspectos del intercambio: el de la producción y el de la recepción y distribución. A nivel de competencia entre sociedades, habrá ventaja para aquella que tenga la mayor productividad y la mejor organización de la producción y de la redistribución.

Entonces, existen poderosos alicientes económicos para fomentar "alguna forma de liderazgo" que administre la producción, la especialización, la redistribución y el intercambio. Pero ¿qué factores adicionales provocan que los líderes administradores se conviertan en jefes, con status elevado respecto de los administrados?. Dice Service, 1971:139):

Cuando la posición del redistribuidor se consolida, éste puede mejorar la condición del intercambio subvencionando a los productores especializados para que eleven la calidad de sus productos. Lo puede hacer pues tiene acceso a los productos, unos para el intercambio y otros para situaciones de emergencia, incluso la guerra. Al convertirse la jefatura en un cargo permanente, surge la diferenciación social como una característica de la sociedad cacical. A la diferenciación social pronto le sigue la diferenciación del consumo. El cargo requiere de responsabilidad y buen juicio y confiere rango alto.

Sin embargo, el rango conferido es susceptible de competencia por quienes consideran que tienen mejores derechos, sea por herencia o por considerar irresponsable y deficiente en juicio a quien quisieran suplantar. En este tipo de conflicto, también es de extrema importancia el simbolismo ideológico, así como las normas y restricciones clánicas que determinan los oficios y posibilidades de sus miembros.

Aún cuando estas normas y restricciones son conocidas en situaciones etnográficas, su visibilidad arqueológica es muy limitada y depende mucho de las deducciones y suposiciones que se hacen con base en alguna iconografía y ciertas prácticas funerarias.

Con respecto al tema de la fuerza de trabajo disponible para "obras públicas", Service (1971) tiene muy poco que decir. Reconoce que este aspecto es muy importante y lo describe como "la habilidad del cacique para planificar, organizar y desplegar fuerza de trabajo" lo cual "puede en muchos casos y bajo ciertas circunstancias, tener consecuencias económicas tremendas para una 
sociedad." Pero cita ejemplos que, a la postre no son de mayor consecuencia social en cacicazgos sino en sociedades estatales. De hecho, es nuestra impresión que en sociedades cacicales, las "obras públicas" y la artesanía especializada, solamente reflejan e intentan reforzar, los rangos enaltecidos de los jefes, en la forma de manifestación del poder y del consecuente consumo diferencial. En este sentido, tales obras poseen una carga simbólica importante, ilustrativa de los merecimientos de los caciques vis a vis las limitaciones del común de las gentes, por razón en ambos casos de sus respectivos statuses.

Las contribuciones de Morton Fried (1967) encontraron un canal de aplicación en la arqueología de Costa Rica, gracias a un trabajo realizado por Michael J. Snarskis (1987), en el cual selecciona una lista de atributos de las sociedades cacicales o de rangos, que considera son los que mejor posibilidad tienen de ser reconocidos en contextos arqueológicos, de manera que los confronta con la evidencia arqueológica. En contraste con el reconocimiento de diferentes tipos de cacicazgos que otros autores proponen y aplican (ej. Sahlins, 1958; Helms, 1979) Snarskis considera a los cacicazgos como una sola categoría homogénea.

Esta situación de singularidad pudiera haber ocurrido en alguna región específica, pero no encuentra expresión ni sustento en la evidencia arqueológica de la cuenca del ReventazónParismina ni del Sarapiquí, en Costa Rica. En estas dos regiones son discernibles arqueológicamente dos tipos de cacicazgos, los que distinguimos bajo términos diferentes: cacicazgos redistributivos, los más antiguos; y cacicazgos absolutistas y polarizados, los más recientes.

La lista de características de los cacicazgos que examina Snarskis (1987) es la siguiente:

- Ambiente: las sociedades cacicales/de rangos ocupan partes ricas, variadas o deseables de la tierra, mientras que las sociedades igualitarias tienden a ocupar tierras marginales.

- Demografía: las sociedades cacicales/de rangos, en comparación con las sociedades igualitarias, tienen una tasa mucho más alta de crecimiento poblacional y mayor densidad demográfica.

- Economía: las sociedades cacicales/de rangos tienen una provisión más segura de alimentos, más concentrada y usualmente domesticada. La redistribución de bienes es clave para mantener el orden social. Se desarrolla la especialización del trabajo, según sexo, edad o necesidades específicas de la sociedad (artesanos). Aparecen los objetos suntuarios que denotan rangos.

- Patrones de asentamiento: predomina el sedentarismo. Las sociedades cacicales/de rangos tienen en un mismo área, mayor número de sitios, de mayor tamaño y más densamente concentrados.

- Relaciones exteriores: la guerra es común, usualmente estimulada por la competencia por recursos. Podría ocurrir intercambio en niveles de media y larga distancia.

Las características ambientales citadas por Snarskis (1987) corresponden a una situación muy común en las sociedades modernas, en las que los pueblos indígenas han sido desplazados de sus territorios, pero no corresponden con los sistemas sociopolíticos prehispánicos de las regiones del Atlántico Norte y Central de Costa Rica. Los estudios arqueológicos en estas dos regiones 
demuestran que en Turrialba y en Sarapiquí, tanto las tribus del Período Formativo como los cacicazgos del Período de Integración Cacical tendieron a ocupar los mismos territorios. Un análisis regional de la evidencia arqueológica del Diquís y del Intermontano Central seguramente mostraría un patrón similar. Sin embargo, parece ser que los cacicazgos tendieron a relacionarse con el ambiente y los recursos en forma versátil. En unos casos ampliaron e intensificaron el uso de sus territorios respondiendo a necesidades de recursos más diversos y especializados, como ocurrió en la cuenca del Sarapiquí (Hurtado de Mendoza, 2005); en otros casos debieron retirarse de territorios que perdieron su capacidad de carga para concentrarse en zonas adyacentes ricas en recursos, como ocurrió en la región de Miravalles-Tempisque (Hurtado de Mendoza y Alvarado, 1988).

Las características poblacionales de crecimiento y mayor densidad, al sobrevenir los cacicazgos, que cita Snarskis (1987), son acertadas y muy evidentes cuando se observan y comparan los patrones de asentamiento de una sociedad tribal con otra cacical. Se multiplican los sitios, en la segunda, y se distribuyen por todos los ambientes y zonas ecológicas, denotando el éxito de los cacicazgos redistributivos vis a vis los cacicazgos totalitarios, pues estos últimos tienden a la centralización y nucleización, en detrimento de los asentamientos periféricos.

Las características económicas, por otro lado, no debieran tratarse como un paquete único y homogéneo propio de todos los cacicazgos, como lo hace Snarskis. Aquí es crítica la distinción entre los cacicazgos redistributivos y los cacicazgos absolutistas, totalitarios o radicalizados. Los objetos suntuarios parecen ser más generalizados cuando un cacicazgo se radicaliza. No lo son tanto cuando un cacicazgo es esencialmente redistributivo. Las causas por las que un cacicazgo pasa de una condición a otra todavía están por ser averiguadas, pero está comprobada la existencia de diferentes tipos de cacicazgos, cada cual con sus propios arreglos económicos (Sahlins, 1958; Helms, 1979). En este aspecto, también se debiera tener en cuenta a Service (1971), cuando propone que los cacicazgos no dependen para su transformación de alguna tecnología innovativa, sino de la intensificación y organización de lo ya conocido para generar excedentes y administrarlos.

Respecto de los patrones de asentamiento, no es desconocida la vinculación del sedentarismo en aldeas con tierras adecuadas para la agricultura, pero esto no solo ocurre en los cacicazgos sino también en tribus. En el caso de éstas, sin embargo, los patrones de asentamiento están bastante bien ilustrados, siendo notoria la habitación en aldeas multifamiliares y la ocurrencia de procesos de fisión-fusión de las aldeas, no tanto por competencia económica sino social-reproductiva (cf. Chagnon, 1973).

En el caso de los cacicazgos y sus patrones de asentamiento, nuevamente es necesario distinguir entre los dos tipos principales de cacicazgos, pues muestran marcadas diferencias. En un cacicazgo redistributivo, según los datos arqueológicos de Turrialba, Suerre y Sarapiquí, es cierto que aumenta el número de sitios pero estos no necesariamente son más grandes ni más densamente concentrados (si con el término se refiere a nucleización). Incluso en los sitios centrales, en donde presuntamente residían los caciques, la monumentalidad que se manifiesta en diversos grados de magnitud, no implica concentraciones de la población significativamente mayores, sino que se limita a la familia del cacique, seguramente poligámica y extensa, y con 
ciertos allegados. La mayor proporción de la población continuaba ampliamente dispersa, en asentamientos unifamiliares, por todo el territorio. El segundo tipo de cacicazgos, el que aquí calificamos de absolutista y radical, ciertamente polarizado en cuanto a diferenciación social, se muestra arqueológicamente con un número de sitios periféricos que tiende a disminuir, mientras los sitios principales, relativamente pocos, aumentan considerablemente en tamaño superficial y en monumentalidad, al parecer denotando nucleización y concentración de más población en ellos.

Finalmente, con respecto a la guerra, es factible que los caciques tuvieran que defender territorios y rutas de intercambio, pero no se puede descartar la posibilidad de que, a medida que el cacicazgo se radicalizaba, se hacía más perentoria la necesidad de sofocar competencia interna por el poder, así como mantener a la población bajo control, dada su potencial inconformidad por la diferenciación en el consumo y la creciente escasez de productos de intercambio. Helms (1979), por ejemplo, considera que la guerra no era de incumbencia de la gente común, sino que habría estado focalizada respecto de los bohíos de los caciques, cuyos asentamientos mostraban estructuras defensivas en tiempos del contacto. Describe murallas de piedras en Comogro; palizadas y profusión de cactuses columnares en el Oeste de Escoria. En ambos casos, la magnitud de estas defensas excede las necesidades de defensa contra animales o un improbable reclamo de privacidad.

El cuadro que sigue, ofrece un compendio de las comparaciones efectuadas por Snarskis (1987) entre atributos teóricos de los cacicazgos y las evidencias arqueológicas. En la penúltima fila se han agregado listas de sitios arqueológicos de la cuenca del Reventazón-Pacuare, que se relacionan con tales evidencias, distribuidas por fases culturales. La última fila muestra los niveles de integración sociopolítica que inferimos, distinguiendo los dos tipos de cacicazgos que discernimos.

Atributos de los cacicazgos y evidencias arqueológicas

\begin{tabular}{|c|c|c|c|}
\hline Atributos & $\begin{array}{c}\text { La Montaña } \\
(2000-200 \text { a.C. })\end{array}$ & $\begin{array}{l}\text { El Bosque-La Selva } \\
\text { (200 a.C.-800 d.C.) }\end{array}$ & $\begin{array}{c}\text { La Cabaña } \\
\text { (800-1500 d.C.) }\end{array}$ \\
\hline Demografía & $\begin{array}{l}\text { Poca población } \\
\text { Baja densidad } \\
\text { Pocos sitios muy } \\
\text { dispersos } \\
\text { Buenos suelos }\end{array}$ & $\begin{array}{l}\text { Mucho más población } \\
\text { Mayor densidad } \\
\text { Muchos sitios } \\
\text { Buenos suelos }\end{array}$ & $\begin{array}{l}\text { Alguna reducción de la población } \\
\text { Nucleización en sitios centrales } \\
\text { Se reduce el número de sitios } \\
\text { Buenos suelos }\end{array}$ \\
\hline Economía & $\begin{array}{l}\text { Agricultura vegetativa } \\
\text { Poca especialización } \\
\text { No hay objetos } \\
\text { suntuarios } \\
\text { Cacería es importante } \\
\end{array}$ & $\begin{array}{l}\text { Vegecultura y semicultura } \\
\text { Especialización artesanal } \\
\text { Objetos suntuarios } \\
\text { Diferenciación funeraria }\end{array}$ & $\begin{array}{l}\text { Vegecultura y semicultura } \\
\text { Especialización artesanal } \\
\text { Objetos suntuarios sofisticados } \\
\text { Diferenciación funeraria marcada }\end{array}$ \\
\hline Asentamientos & $\begin{array}{l}\text { Sitios pequeños } \\
\text { Muy dispersos } \\
\text { Sin estructuras } \\
\text { Basureros solamente }\end{array}$ & $\begin{array}{l}\text { Sitios sencillos } \\
\text { Ampliamente distribuidos } \\
\text { Basamentos cuadrangulares } \\
\text { Cementerios grandes } \\
\text { Tumbas cajón o corredor } \\
\text { Inicios de monumentalidad }\end{array}$ & $\begin{array}{l}\text { Sitios complejos y sitios sencillos } \\
\text { Tendencia a la dispersión } \\
\text { Montículos y basamentos redondos } \\
\text { Cementerios grandes } \\
\text { Tumbas de cajón (lajas y bloques) } \\
\text { Exaltación de monumentalidad }\end{array}$ \\
\hline
\end{tabular}




\begin{tabular}{|c|c|c|c|}
\hline Atributos & $\begin{array}{c}\text { La Montaña } \\
(2000-200 \text { a.C. })\end{array}$ & $\begin{array}{l}\text { El Bosque-La Selva } \\
\text { (200 a.C.-800 d.C.) }\end{array}$ & $\begin{array}{c}\text { La Cabaña } \\
(800-1500 \text { d.C. })\end{array}$ \\
\hline $\begin{array}{l}\text { Relaciones } \\
\text { externas }\end{array}$ & $\begin{array}{l}\text { Cerámica sofisticada } \\
\text { (CB) } \\
\text { Poco intercambio } \\
\text { (cerámica) }\end{array}$ & $\begin{array}{l}\text { Guerra (figuras de guerreros } \\
\text { y culto cabeza-trofeo } \\
\text { Dos complejos cerámicos } \\
\text { Intercambio de objetos } \\
\text { suntuarios } \\
\text { (jade, espejos, cerámica fina) }\end{array}$ & $\begin{array}{l}\text { Intercambio de objetos suntuarios } \\
\text { (oro, hachas pulidas, adornos, } \\
\text { metates) } \\
\text { Cerámica muy decorada } \\
\text { Conflicto interno/externo } \\
\text { Invasión y dominio de los Huetares }\end{array}$ \\
\hline Sitios & $\begin{array}{l}\text { La Montaña } \\
\text { Guayabo } \\
12 \text { sitios Región } \\
\text { Guayabo } \\
12 \text { sitios Valle Turrialba } \\
1 \text { sitio Ta'Lari }\end{array}$ & $\begin{array}{l}\text { Severo Ledesma } \\
\text { Las Mercedes } \\
\text { Guayabo } \\
\text { Zapote-2 } \\
25 \text { sitios en región Guayabo } \\
98 \text { sitios en Valle Turrialba } \\
3 \text { sitios en región Ta'Lari } \\
\text { El Escobal de Pacuare }\end{array}$ & $\begin{array}{l}\text { Las Mercedes } \\
\text { Bremen } \\
\text { Ta'Lari } \\
\text { Aguacaliente } \\
\text { Guayabo } \\
\text { La Cabaña } \\
\text { Finca Costa Rica } \\
\text { Nájera } \\
\text { La Zoila } \\
100 \text { sitios en Guayabo, Turrialba y } \\
\text { Ta'Lari }\end{array}$ \\
\hline $\begin{array}{l}\text { Nivel } \\
\text { sociopolítico }\end{array}$ & Tribal & Cacical redistributivo & Cacical absolutista-polarizado \\
\hline
\end{tabular}

El estudio de Helms (1979) en Panamá es excepcionalmente ilustrativo en lo que respecta a los patrones de asentamiento de las sociedades cacicales en el siglo XVI. Con base en Oviedo (1853) describe casas distribuidas "aquí y allá", cerca del agua, en los valles y laderas de las montañas, sugiriendo cercanía de tierras de cultivo. Citando a Anghera (1912) expone dos ejemplos:

- Comogre: casa grande de 150x80 pasos (45x24 metros), con paredes de troncos atados unos con otros, y reforzadas con murallas de piedras. El cielorraso estaba tallado y el piso estaba "decorado artísticamente". Tenía despensa y buhardilla, muy llenas de provisiones. Esta residencia cacical tenía aparentemente varias habitaciones y en la parte más interna había una cámara con los cuerpos disecados de los ancestros muertos, lujosamente vestidos y suspendidos mediante sogas de acuerdo al rango que habían tenido en vida.

- Tumanama: residencia del cacique Tubanama, en la cual había dos casas largas, cada una de 220x50 pasos (66x15 metros), construidas para albergar guerreros.

Estos ejemplos, coinciden con los de Meléndez (1978) quien cita las observaciones de Juan Dávila en 1566 respecto de dos casas en la provincia de los Votos, la mayor de las cuales tenía unos 60x12 metros, pero también indica que la población estaba "derramada por la montaña", que "no estaba toda junta, sino cada bohío por si". También la casa en Suerre, descrita por Benzoni, destaca por su aislamiento y su tamaño excepcional: $45 \times 9$ pasos $(27 \times 5$ metros aproximadamente); y en Talamanca, Vázquez de Coronado se asombró ante la dispersión de las casas de los indios, carentes de palizadas y que "nunca vio tres casas juntas", siendo aún más magra la situación en el Valle Central, en donde "las aldeas de los güetares eran pequeñas, y en algunos casos consistían en sólo dos o tres casas comunales" (cf. Lothrop, 1926). En suma, la mayor parte de la población en estas regiones, al igual que en Panamá, vivía en asentamientos 
extremadamente dispersos y las casas de los caciques, a pesar de su tamaño mayor, no pasaban de una o dos estructuras.

Después de su exploración de la literatura especializada (eg. Anghera, 1912; Lothrop, 1937; Young, 1971), Mary Helms (1979) arribó a la conclusión de que las aldeas como Natá debieron ser lugares donde vivía algún cacique con solamente su familia y allegados, mientras que el resto de la población vivía en asentamientos dispersos y alejados.

Para nuestros fines de interpretación del Monumento Nacional Guayabo, estos datos son de importancia crítica, pues, en una evidente mayoría de casos se aprecia que los centros de poder cacical fueron asentamientos con estructuras de mayor dimensión, pero número reducido a una o dos casas grandes. Esta condición básica, seguramente fue la que predominó en Guayabo a lo largo de la mayor parte de su desarrollo, el cual, prolongado como fue, dio lugar a un número apreciable de estructuras que, no necesariamente todas funcionaron a un mismo momento, sino que resultaron de la acumulación de muchos pares de estructuras, algunos de los cuales pudo contar también con otras estructuras accesorias, algunas sin duda imponentes, en épocas del mayor esplendor.

El trabajo de Helms (1979) también contribuye en un aspecto metodológico crítico para la arqueología, el cual busca detectar la diferenciación social típica de una sociedad cacical, no solamente en razón de la existencia de sitios centrales con rasgos arquitectónicos, sino también mediante la comparación de tales sitios con los del común de las gentes, haciendo evidente e incuestionable la polarización de sus características.

El tamaño del bohío del cacique seguramente reflejaba su status y poder, pero debe tenerse en cuenta que su tamaño también debe ser una consecuencia de otras variables conexas. Por ejemplo, desde tiempos tribales existía poligamia diferencial, de manera que se puede esperar que los caciques también destacaran por tener una familia más numerosa que el común de la gente, requiriendo por lo tanto más espacio habitacional; por otro lado, la función redistributiva del cacique requiere de infraestructura para el almacenamiento de los productos que están en la agencia central, esperando ser redistribuidos o intercambiados. Este requerimiento no parece haber sido insignificante. En Comogre se ocupaba una despensa y una buhardilla, pero contenían suficientes provisiones como para permitirles grandes comilonas a los españoles. Las casas largas de Tumanama, antes que solamente guerreros, podrían haber albergado esposas y sus hijos, parientes, y también pudieron servir para almacenar productos de intercambio y de redistribución.

El trabajo de Helms (1979), por otro lado, es una importante contribución para superar la noción de que los cacicazgos constituyeron una sola categoría homogénea, pues su análisis revela al menos dos de las sub-categorías que proponen Sahlins (1958) y Goldman (1970) con base en sus observaciones en la Polinesia.

Las variables caracterizadoras de los cacicazgos que enumera y estudia Sahlins (1958), son las siguientes: 
- Número de niveles de status o rangos en la sociedad.

- Grado relativo de accesibilidad a los recursos por la nobleza y el pueblo.

- Monto y tipo de control de la producción por la nobleza.

- Naturaleza de la jerarquía de redistribución.

- Énfasis en las insignias del rango.

- Grado de control cacical de procesos socioregulatorios.

- Naturaleza de los matrimonios cacicales.

- Formas de obediencia respecto de los caciques.

- Distinciones de los ritos de crisis vitales entre caciques y no-caciques.

Las evidencias que Helms (1979) encuentra en los cacicazgos panameños, respecto de tales variables, son las siguientes:

En cuanto a rangos, encuentra una composición compleja en la cual existen personas de varios rangos: los caciques principales (quevís); los caciques supeditados (sacos) usualmente familiares del queví o jefes conquistados; los çabras, de status bajo en la élite incluyendo familiares lejanos o guerreros emergentes del nivel popular; el pueblo, sin rango, diferenciado por la vestimenta, normas matrimoniales y ritos; y los pacos cuya condición es de esclavos, originalmente prisioneros de guerra.

En cuanto a tributos, Helms (1979) no encuentra ninguno que estuviera establecido con alguna regularidad, pero los que existían tenían la forma de servicios personales y trabajo para cubrir las necesidades particulares de los caciques, por ejemplo la construcción de su casa, el cultivo de maíz para el cacique y el aprovisionamiento de vituallas en tiempos de guerra. Sin embargo, en retribución, el cacique debía distribuir alimentos y bebidas.

En cuanto a los especialistas, Helms (1979) detecta pescadores en la costa; maestros "tequina" que se destacaban por su habilidad para la cacería, la pesca y extracción de mariscos, la elaboración de redes, de cerámica y orfebrería de oro, la manufactura de armas, el canto, la música, y el contacto supernatural.

Las normas matrimoniales, aparentemente prescribían la endogamia de status, pero el cacique tenía las mujeres que quisiera aunque solo una era la formal. En todo caso, solamente los hijos de la esposa formal heredaban el rango.

En cuanto a los roles de los caciques, Helms (1979) nota que los quevís resolvían disputas, riñas, asuntos de moral, de paz y orden; y aplicaban la pena de muerte cuando alguien les mentía.

En lo que respecta a insignias del rango, la élite se distinguía por su vestimenta y ornamentos, las tallas en la madera de la vivienda y los utensilios que utilizaban, todo lo cual estaba ostensiblemente dirigido a denotar en forma simbólica la estatura social preeminente, el poder y santidad del cacique. Además, el cacique debía destacarse como persona espléndida, capaz de ofrecer fiestas y comilonas en las que había largueza y abundancia. 
En lo que concierne a la variable de formas de obediencia, Helms (1979) informa que existían marcas tatuadas que identificaban la relación de cada individuo respecto de un cacique. Por otro lado, era un requisito ostensible e imprescriptible que, cuando viajaba, el cacique debía ser transportado en una hamaca.

Finalmente, existían diferencias notables en el tratamiento ritual relacionado con las crisis vitales. Al morir un comunitario "su alma muere junto con su cuerpo" de manera que no se requiere de ritos. En claro contraste, al morir un cacique se suscitaba un ritual elaborado justificado por la certeza ideológica de que los caciques tienen vida ulterior, la que pueden compartir con sus esposas y todo aquel que los desee acompañar mediante sacrificio o suicidio. Los restos de un cacique eran disecados, envueltos en mantas finas y debían conservar sus insignias de rango, incluyendo sus joyas y ornamentos. Se les enterraba o se les mantenía en fardos funerarios, en un recinto especial dentro de la vivienda, junto con sus ancestros.

Para nuestros fines de aplicación arqueológica, hemos seleccionado las características ilustradas por Helms (1979) que poseen visibilidad arqueológica en el Monumento Nacional Guayabo. Siguiendo el mismo procedimiento analítico de dicha investigadora, logramos discernir aquellas características que parecen pertenecer a uno u otro de dos tipos de cacicazgos de Sahlins.

El siguiente cuadro resume los resultados del ejercicio y agrega información acerca del potencial de las entidades arqueológicas para ilustrar objetivamente cada variable.

El Análisis de Helms, aplicado al Monumento Nacional Guayabo

\begin{tabular}{|l|c|c|l|}
\hline \multicolumn{1}{|c|}{ Características } & $\begin{array}{c}\text { Sahlins } \\
\text { Iia }\end{array}$ & $\begin{array}{c}\text { Sahlins } \\
\text { IIb }\end{array}$ & \multicolumn{1}{c|}{ Visibilidad Arqueológica } \\
\hline Dos-tres niveles de status & $\mathrm{X}$ & & $\begin{array}{l}\text { Iconografía en petroglifos conmemorativos } \\
\text { Patrones de asentamiento: gradiente en tamaños de } \\
\text { los sitios y en los grados de intensidad en uso de la } \\
\text { cerámica. } \\
\text { Diferenciación en tumbas y ofrendas funerarias. }\end{array}$ \\
\hline Dos niveles de status & $\mathrm{X}$ & $\begin{array}{l}\text { Patrones de asentamiento: dos categorías en } \\
\text { asentamientos radicalmente distintas. } \\
\text { Diferenciación en tumbas y ofrendas funerarias. }\end{array}$ \\
\hline $\begin{array}{l}\text { Administración } \\
\text { preeminente de recursos } \\
\text { por el cacique principal }\end{array}$ & $\mathrm{X}$ & $\begin{array}{l}\text { Distribución equitativa de cerámica entre todos los } \\
\text { asentamientos (frecuencias relativas). }\end{array}$ \\
\hline $\begin{array}{l}\text { Mayor acceso a recursos } \\
\text { clave por parte de los } \\
\text { caciques }\end{array}$ & $\mathrm{X}$ & $\begin{array}{l}\text { Distribución copiosa de cerámica en asentamientos } \\
\text { centrales; y escasa en los asentamientos periféricos. }\end{array}$ \\
\hline $\begin{array}{l}\text { Posible confiscación de } \\
\text { tierras de comunes }\end{array}$ & $\mathrm{X}$ & $\mathrm{X}$ & $\begin{array}{l}\text { Patrones de asentamiento (reducción drástica de } \\
\text { asentamientos periféricos) }\end{array}$ \\
\hline $\begin{array}{l}\text { No existen confiscaciones } \\
\text { de tierras de los comunes }\end{array}$ & \begin{tabular}{l} 
Persistencia numérica de asentamientos periféricos. \\
\hline $\begin{array}{l}\text { Jerarquía redistribuiva en } \\
\text { dos niveles }\end{array}$
\end{tabular} & $\begin{array}{l}\text { Bienes de intercambio inter-regional entre caciques } \\
\text { y entre élites de centros locales. }\end{array}$ \\
\hline $\begin{array}{l}\text { Los caciques como foco } \\
\text { de la redistribución }\end{array}$ & $\begin{array}{l}\text { Equidad o tenue gradiente entre tamaños de } \\
\text { asentamiento y acceso a cerámica. }\end{array}$ \\
\hline
\end{tabular}




\begin{tabular}{|c|c|c|c|}
\hline Características & $\begin{array}{c}\text { Sahlins } \\
\text { Iia }\end{array}$ & $\begin{array}{l}\text { Sahlins } \\
\text { IIb }\end{array}$ & Visibilidad Arqueológica \\
\hline $\begin{array}{l}\text { Marcadas insignias de } \\
\text { rango }\end{array}$ & $\mathrm{X}$ & & $\begin{array}{l}\text { Patrones de asentamiento. } \\
\text { Prácticas funerarias. } \\
\text { Consumo diferencial de bienes. }\end{array}$ \\
\hline Pocas insignias de rango & & $\mathrm{X}$ & $\begin{array}{l}\text { Patrones de asentamiento. } \\
\text { Prácticas funerarias. } \\
\text { Consumo diferencial de bienes. }\end{array}$ \\
\hline $\begin{array}{l}\text { Grado aceptable de } \\
\text { autoridad arbitraria }\end{array}$ & $\mathrm{X}$ & & Iconografía / estatuaria (ej. cabezas trofeo) \\
\hline $\begin{array}{l}\text { Grado limitado de } \\
\text { autoridad arbitraria }\end{array}$ & & $\mathrm{X}$ & Iconografía / estatuaria (ej. no hay cabezas trofeo) \\
\hline $\begin{array}{l}\text { Penas severas en contra de } \\
\text { quien infrinja la autoridad } \\
\text { del cacique }\end{array}$ & $\mathrm{X}$ & & Iconografía / estatuaria (ej. cabezas trofeo) \\
\hline $\begin{array}{l}\text { Penas violentas son raras y } \\
\text { se apela a refuerzos } \\
\text { supernaturales }\end{array}$ & & $\mathrm{X}$ & Iconografía / estatuaria (ej. no hay cabezas trofeo) \\
\hline $\begin{array}{l}\text { Matrimonio intrastatus de } \\
\text { los caciques pero no } \\
\text { cumplido rigurosamente }\end{array}$ & $\mathrm{X}$ & & $\begin{array}{l}\text { Examen comparativo de ofrendas funerarias vs } \\
\text { cercanía física de tumbas en cementerios. }\end{array}$ \\
\hline $\begin{array}{l}\text { Cierto apego a normas } \\
\text { matrimoniales intrastatus }\end{array}$ & & $\mathrm{X}$ & $\begin{array}{l}\text { Examen comparativo de ofrendas funerarias vs } \\
\text { cercanía física de tumbas en cementerios. }\end{array}$ \\
\hline $\begin{array}{l}\text { Posturas de obediencia } \\
\text { poco enfáticas }\end{array}$ & $\mathrm{X}$ & & Iconografía (ej. caciques llevados en hamacas) \\
\hline $\begin{array}{l}\text { Pocas o ninguna postura } \\
\text { de obediencia }\end{array}$ & & $\mathrm{X}$ & $\begin{array}{l}\text { Iconografía (ej. cacique preeminente entre el } \\
\text { común) }\end{array}$ \\
\hline $\begin{array}{l}\text { Ritos especiales en las } \\
\text { crisis vitales en las } \\
\text { familias de los caciques }\end{array}$ & $\mathrm{X}$ & & Prácticas funerarias. \\
\hline $\begin{array}{l}\text { Poca diferencia en grado } \\
\text { pero no en esencia entre } \\
\text { los ritos de caciques y el } \\
\text { común }\end{array}$ & & $\mathrm{X}$ & $\begin{array}{l}\text { Prácticas funerarias. } \\
\text { Iconografía. }\end{array}$ \\
\hline
\end{tabular}

Esta tabla está basada en los datos etnohistóricos y etnográficos que ofrece Helms (1979), los cuales representan una etapa relativamente corta y afectada por el contacto, en el desarrollo de los cacicazgos panameños. Para su aplicación en contextos arqueológicos es importante que se tenga en cuenta las diferencias que son perceptibles entre períodos y entre fases culturales dentro de algunos períodos. En las cuencas del Reventazón y del Sarapiquí se podría postular que la evidencia arqueológica e histórica revela una secuencia de cambio sociopolítico, como sigue:

Secuencia de cambio sociopolítico en las cuencas del Reventazón y Sarapiquí

\begin{tabular}{|l|c|c|l|}
\hline \multirow{2}{*}{ Períodos } & \multicolumn{2}{c|}{ Cronología } & \multirow{2}{*}{ Nivel de Integración Sociopolítica } \\
\cline { 2 - 3 } & Inicial & Final & \\
\hline Paleoindio & $9000 \mathrm{AC}$ & $7000 \mathrm{AC}$ & Sociedad de bandas \\
\hline Arcaico & $7000 \mathrm{AC}$ & $2000 \mathrm{AC}$ & Sociedad de bandas \\
\hline Formativo Medio & $2000 \mathrm{AC}$ & $200 \mathrm{AC}$ & Sociedad tribal \\
\hline Integración Cacical I & $200 \mathrm{AC}$ & $800 \mathrm{DC}$ & Sociedad cacical redistributiva (Tipo Sahlins IIb) \\
\hline Integración Cacical II & $800 \mathrm{DC}$ & $1500 \mathrm{DC}$ & Sociedad cacical absolutista (Tipo Sahlins IIa) \\
\hline
\end{tabular}




\begin{tabular}{|l|c|c|l|}
\hline \multirow{2}{*}{ Períodos } & \multicolumn{2}{c|}{ Cronología } & \multirow{2}{*}{ Nivel de Integración Sociopolítica } \\
\cline { 2 - 3 } & Inicial & Final & \\
\hline Colonial & $1500 \mathrm{DC}$ & $1821 \mathrm{DC}$ & $\begin{array}{l}\text { Sociedad estatal absolutista (reinado e imperio } \\
\text { europeos) }\end{array}$ \\
\hline Republicano & $1821 \mathrm{DC}$ & $2008 \mathrm{DC}$ & Sociedad estatal democrática y representativa \\
\hline
\end{tabular}

\section{Historia cultural de Guayabo de Turrialba}

El Monumento Nacional Guayabo es un sitio arqueológico multicomponente (Aguilar, 1972). Las investigaciones arqueológicas realizadas en la década de los años 80, tanto en el sitio Guayabo como en múltiples localidades de la región, produjeron abundante material cerámico que fue identificado como correspondiente a cuatro complejos cerámicos de la cuenca del Reventazón-Parismina: La Montaña; El Bosque; La Selva; y La Cabaña (Hurtado de Mendoza \& Gómez 1985; Hurtado de Mendoza, 2002, 2004). Con base en la tipología original de Aguilar para el Valle Central y Turrialba, estos complejos fueron caracterizados por Snarskis (1978), constituyendo el parámetro modal y tipológico que se aplica rutinariamente en los estudios arqueológicos de la Vertiente Central del Atlántico.

Sin embargo, la secuencia cronológica de estos complejos, propuesta por Snarskis, es motivo de debate desde dos décadas atrás (Hurtado de Mendoza \& Arias, 1983), de manera que en este trabajo se considera que la historia ocupacional del Monumento Nacional Guayabo se hace evidente por la ocurrencia de cerámica de los cuatro complejos arriba descritos, pero representando únicamente dos períodos, el segundo de los cuales consta de dos fases, como sigue:

\section{Periodificación prehispánica del Monumento Nacional Guayabo}

\begin{tabular}{|c|c|c|}
\hline Período / Fase & Fechas & Complejos Cerámicos \\
\hline Formativo Medio & $2000-200$ a.C. & La Montaña \\
\hline Integración Cacical - I & 200 a.C. -800 d.C. & El Bosque / La Selva \\
\hline Integración Cacical - II & $800-1500$ d.C. & La Cabaña \\
\hline
\end{tabular}

Durante el período Formativo, la ocupación en Guayabo es evidente pero modesta, muy dispersa por diversas localidades dentro del área general del sitio. Se nota cierta tendencia a que la cerámica La Montaña esté vinculada con nacientes y arroyos, antes que con quebradas y ríos. No se tiene indicio de que en este período pudiera haberse iniciado el proceso constructivo. Una fecha de radiocarbono (Beta-12345) obtenida para el estrato inferior del Montículo Principal del sitio, indujo a que Troyo y Garnier (2002) propusieran la etapa inicial de construcciones en el lapso de los años 530 al 390 a.C., esto es, en los últimos siglos del período Formativo. Sin embargo, los investigadores hallaron asociación cultural de la estructura con cerámica El Bosque, principalmente, la cual es posterior en el tiempo, respecto del dato cronométrico citado.

Con base en datos de patrones de asentamiento en la región de Turrialba y también de la distribución de cerámica en dichos asentamientos, se ha propuesto que en el período Formativo Medio (2000-200 a.C.), existió una sociedad tribal, con baja densidad poblacional, dedicada a una economía agrícola, complementada con cacería y recolección. 
La cerámica de los complejos El Bosque y La Selva, constituye la proporción mayoritaria del material cerámico en Guayabo, lo cual es interpretado como evidencia de que en la primera fase del período de Integración Cacical, ocurrió el mayor desarrollo socio-político, así como la mayor monumentalidad. Existe una clara correlación entre los sectores con las mayores proporciones de material El Bosque-La Selva y la máxima expresión de monumentalidad. Se ha propuesto que en esta fase (200 a.C.-800 d.C.) se estableció un sistema cacical en Guayabo y en la región de Turrialba, el cual tuvo las características propias de un cacicazgo eminentemente redistributivo, del tipo IIB de Sahlins (1958), pero que devino posteriormente en el tipo IIA, más radical y absolutista.

La transformación a una versión cacical absolutista ocurrió en Guayabo en tiempos de la segunda fase (800-1500) del período de Integración Cacical, según se deduce de la presencia importante de material cerámico del complejo La Cabaña. En esta segunda fase la monumentalidad, aunque presente, se redujo en dimensión pero se incrementó en sofisticación tecnológica y en calidad artística. Se ha propuesto que fue en esta fase tardía cuando se experimentó la mayor polarización social de todo el proceso, lo cual conllevó la destrucción y abandono del sitio, alrededor del año 1300 d.C. Esto no significó debacle mayor para la población regional, pues otros sitios de la cuenca del Reventazón pugnaron por reemplazar a Guayabo en sus diversos roles cacicales.

El siguiente gráfico, muestra la distribución porcentual de los cuatro complejos cerámicos identificados en Guayabo, por sectores del sistema general de coordenadas que se estableció para el sitio con punto de origen encima del Montículo 1 (Fonseca, 1979). De primera intención se les presenta en el orden cronológico que otros proponen, pero también se les grafica, más abajo, conjugando los complejos El Bosque y La Selva, que aquí consideramos como fundamentalmente contemporáneos. En ambos casos, las curvas resultantes ilustran la tendencia ocupacional principal del sitio Guayabo, por sectores, a través del tiempo.

Figura 1

Distribución porcentual de cuatro complejos cerámicos en Guayabo, por sectores del sitio

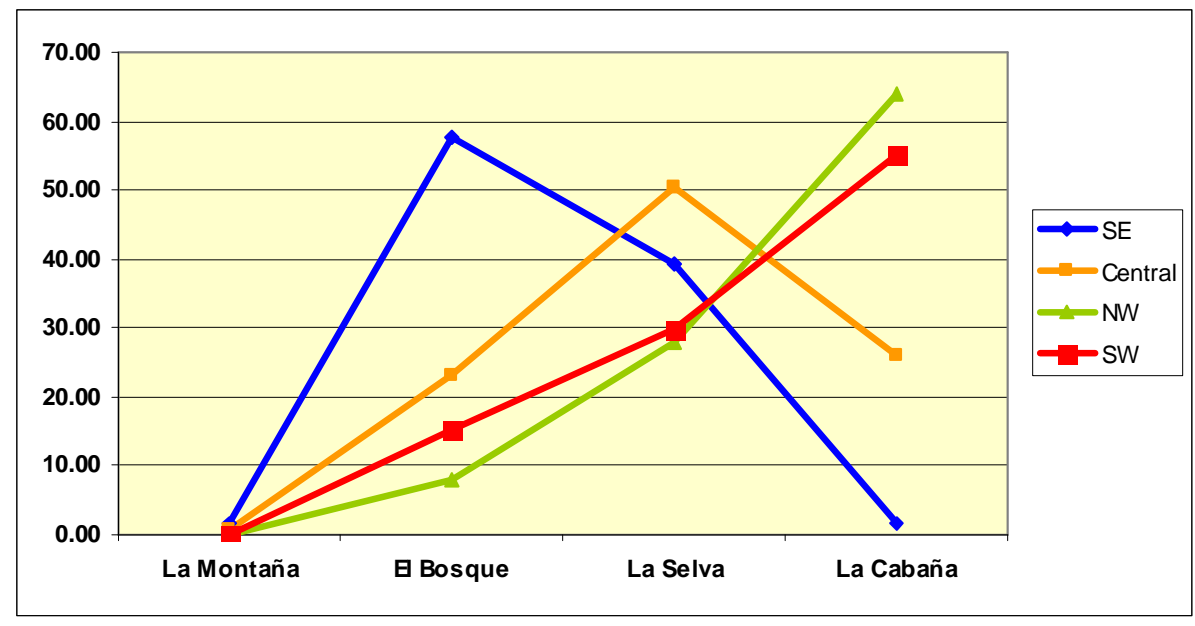


En términos de la distribución de la cerámica en los cuatro sectores del sitio, definidos por el sistema de coordenadas cuyo origen es el punto a (alfa) ubicado encima del Montículo Principal, se observa que los únicos sectores que comparten patrones similares son el NW y el SW (rPearson $=0.99)$, sugiriendo una historia ocupacional similar. El sector Central presenta correlaciones moderadas con todos los otros tres sectores (r-Pearson 0.43 a 0.54 ), denotando un proceso ocupacional congruente con la noción de máximo desarrollo del sitio en este sector, asociado principalmente con la cerámica La Selva. El sector SE muestra un proceso muy diferente, sin correspondencia alguna con los sectores SW y NW.

Al "radicalizar" el análisis, mediante la integración de datos de los complejos El Bosque y La Selva, los cuales se han revelado fundamentalmente coetáneos, con cierta precedencia en el tiempo para El Bosque y alguna continuidad de La Selva en tiempos tardíos, los resultados también se manifiestan como muy polarizados.

Por un lado, los sectores SE y Central muestran procesos similares (r-Pearson $=0.94$ ) en los cuales hallan una situación cúspide en lo que se refiere a los materiales El Bosque-La Selva, pero a esto le sigue una etapa de ocupación atestiguada por magras proporciones de la cerámica tardía La Cabaña, sugiriendo abandono. Por otro lado, los sectores NW y SW en este segundo análisis también presentan una correlación muy alta $(r-P e a r s o n ~=0.97)$, pero esta responde a un proceso diferente, en el cual no se interrumpe la tendencia creciente de la cerámica de los complejos ordenados de acuerdo a su antigüedad relativa. El gráfico es muy ilustrativo de la diferencia entre las historias ocupacionales de los dos pares de sectores (SE-Central y NW-SW). Mientras los primeros aumentan para después decaer; los segundos encuentran su florecimiento en tiempos tardíos, precisamente cuando los otros dos muestran decadencia. Obsérvese el punto crítico que el gráfico muestra, desde el cual la caída de unos se agudiza mientras el incremento de los otros continúa, aunque sin alcanzar los niveles que los sectores SE y Central lograron durante la primera fase del período de Integración Cacical.

Figura 2

Distribución porcentual de la cerámica de tres fases culturales en Guayabo, por sectores del sitio

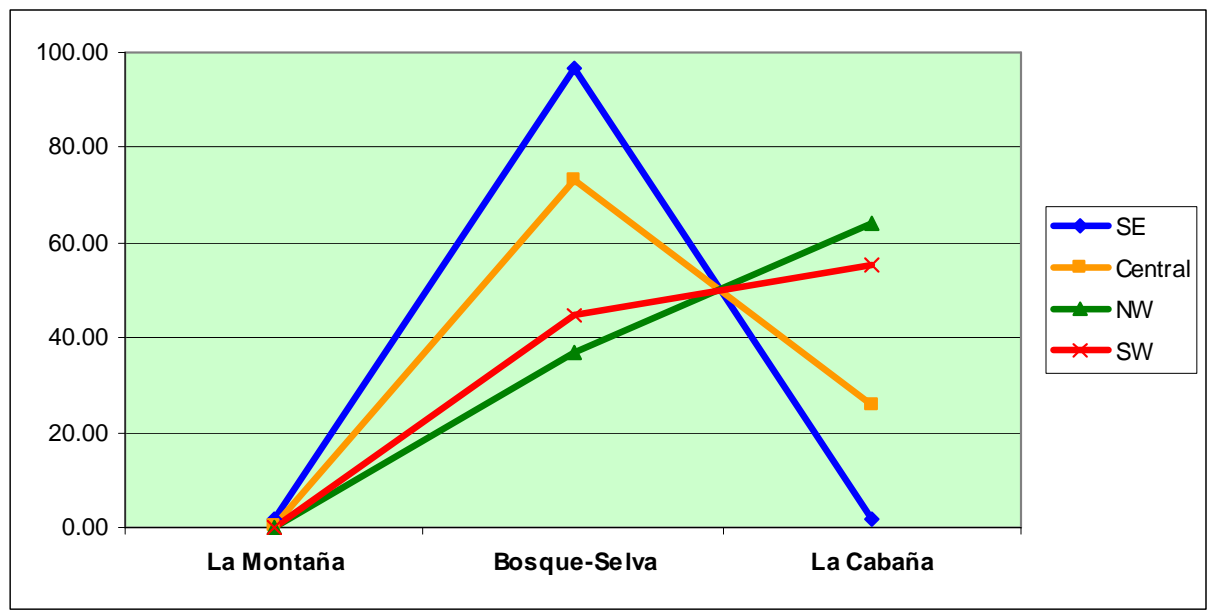




\section{Cronología y monumentalidad}

Guayabo de Turrialba es un sitio multicomponente. En la sección anterior se presentaron datos consistentes acerca de tal condición, la cual refleja una historia ocupacional que podría haber discurrido por más de tres milenios. En tan largo contexto temporal, debiera ser más fácil esperar muchos cambios culturales, incluyendo cambios en la estructura arquitectónica y en la dimensión de la monumentalidad, en donde más se manifiesta la simbología del poder sociopolítico en las sociedades prehispánicas.

Visto de otra manera, no parece razonable esperar que el fenómeno de la monumentalidad sea invariable, ni que se limite a una fase cultural, ni tampoco que ésta sea necesaria ni exclusivamente una fase tardía. Si así fuera, las referencias etnohistóricas debieran estar pletóricas de descripciones de grandes aldeas y ciudades, al menos de las que conocemos arqueológicamente. Los conquistadores se habrían alojado en palacios y habrían contado con abundantes vituallas y riquezas. Pero, no fue así. Las crónicas de tiempos del contacto reflejan todo lo contrario, sin ocultar ni el asombro ni la decepción de los militares, religiosos y administradores españoles del siglo XVI. De hecho, si se acepta la premisa de que el tamaño, naturaleza y complejidad de los asentamientos en una región o país refleja o expresa, simbólicamente o de forma tangible, la dimensión del poder de los caciques, entonces resulta que tal poder no fue muy elevado en la Costa Rica y Panamá de aquellos tiempos.

Así, la hipótesis de "unidad cronológica" de la monumentalidad durante la fase más tardía de la secuencia cultural prehispánica en Costa Rica, no pasa de ser una presunción. También, el reclamo de que existiría en la estructura arquitectónica de los sitios arqueológicos monumentales una cierta "unidad de técnicas y diseños", no parece hallar mayor asidero en la evidencia observable. Es cierto que en todos los casos se utilizó la piedra como el material de construcción más evidente, pero esta observación no parece ser más que el resultado de la mayor resistencia de la piedra a los embates del tiempo y del ambiente. También es evidente que ciertos arreglos arquitectónicos parecen ser los más populares: montículos circulares, calzadas y pisos empedrados, escalinatas, muros de contención. Pero hay otros que discrepan en forma y función o que no se encuentran en todo lugar.

Lo que sigue, intenta sustanciar dos hipótesis alternativas que se contraponen al concepto de "unidad cronológica, de técnicas y diseños". La primera está dirigida a ilustrar la presencia de estructuras monumentales de diferentes períodos y fases culturales en sitios conocidos de Costa Rica. La segunda enfatiza la diversidad de formas y funciones de dichas estructuras en algunos sitios de las regiones de Turrialba, Suerre, San Carlos y Sarapiquí.

El cuadro siguiente, ilustra en forma breve la posición cronológica de los complejos arquitectónicos de los sitios monumentales más conocidos del país. Más abajo se ofrecen datos, en más detalle, que apoyan nuestras conclusiones acerca de la temporalidad de los mismos y su características monumentales. Se utiliza, en este caso, la periodificación arqueológica estándar del istmo centroamericano, de manera que se simplifiquen las correlaciones entre regiones. 
Ubicación Cronológica de Sitios Monumentales en Costa Rica

\begin{tabular}{|c|c|c|c|c|}
\hline Región & Períodos IV-V & Período VI & Sitios & $\begin{array}{c}\text { Investigadores } \\
\end{array}$ \\
\hline Turrialba & $\begin{array}{l}\text { El Bosque-La } \\
\text { Selva }\end{array}$ & La Cabaña & $\begin{array}{l}\text { Guayabo } \\
\text { Nájera (Alto Varas) } \\
\text { La Zoila }\end{array}$ & $\begin{array}{l}\text { Aguilar; Fonseca; Hurtado de } \\
\text { Mendoza } \\
\text { Kennedy; Acuña; Massey, } \\
\text { Sánchez } \\
\text { Snarskis; Vázquez, Massey, } \\
\text { Sánchez }\end{array}$ \\
\hline Suerre & $\begin{array}{l}\text { El Bosque-La } \\
\text { Selva }\end{array}$ & La Cabaña & $\begin{array}{l}\text { Las Mercedes } \\
\text { Anita Grande } \\
\text { Finca Costa Rica } \\
\text { La Cabaña } \\
\text { Williamsburg } \\
\text { Severo Ledesma }\end{array}$ & $\begin{array}{l}\text { Hartman; Gutiérrez, Hurtado de } \\
\text { Mendoza } \\
\text { Skinner } \\
\text { Skinner } \\
\text { Snarskis } \\
\text { Hartman; Stirling; Corrales, } \\
\text { Gutiérrez } \\
\text { Snarskis }\end{array}$ \\
\hline Pacuare & $\begin{array}{l}\text { El Bosque-La } \\
\text { Selva }\end{array}$ & La Cabaña & $\begin{array}{l}\text { Ta Lari } \\
\text { El Escobal }\end{array}$ & $\begin{array}{l}\text { Hurtado de Mendoza, Gómez } \\
\text { Herrera; Hernández }\end{array}$ \\
\hline Telire & Aguas Buenas & Chiriquí & Rangalle & Hurtado de Mendoza \\
\hline Guarco & & Cartago & Aguacaliente & $\begin{array}{l}\text { Hartman; Vázquez, Corrales; } \\
\text { Valerio et al. }\end{array}$ \\
\hline $\begin{array}{l}\text { San } \\
\text { Carlos }\end{array}$ & Ronrón-Platanar & Venecia & Cutris & Guerrero, Troyo \\
\hline Sarapiquí & $\begin{array}{l}\text { Curridabat } \\
\text { Ujarrás }\end{array}$ & $\begin{array}{l}\text { La Cabaña } \\
\text { Cartago } \\
\text { La Isla }\end{array}$ & $\begin{array}{l}\text { Cubujuquí } \\
\text { Sarapiquís } \\
\text { Crucero } \\
\text { Bolaños }\end{array}$ & $\begin{array}{l}\text { Gutiérrez, Mora } \\
\text { Herrera } \\
\text { Guerrero, Troyo } \\
\text { Stirling, Stirling }\end{array}$ \\
\hline Diquís & Aguas Buenas & Chiriquí & $\begin{array}{l}\text { Murciélago } \\
\text { Fuerte Couto } \\
\text { Finca } 6 \\
\text { Batambal }\end{array}$ & $\begin{array}{l}\text { Drolet, Markens } \\
\text { Drolet, Markens } \\
\text { Corrales, Badilla } \\
\text { Badilla, Mora, Navas }\end{array}$ \\
\hline Miravalles & $\begin{array}{l}\text { Naranjo } \\
\text { (Bicromo en } \\
\text { Zonas) }\end{array}$ & & $\begin{array}{l}\text { Murillo (Sitio 10) } \\
\text { Méndez Ramírez } \\
\text { Río Naranjo } \\
\text { Sitios } 2,3,8,13,14 \text {, } \\
15,23\end{array}$ & $\begin{array}{l}\text { Ryder } \\
\text { Norr } \\
\text { Norr } \\
\text { Ryder }\end{array}$ \\
\hline Tenorio & $\begin{array}{l}\text { Policromo } \\
\text { Temprano }\end{array}$ & & Hacienda Jericó & Finch \\
\hline
\end{tabular}

De primera intención, resulta interesante observar que los sitios más conspicuos que cuentan con estructuras monumentales no son exclusivamente tardíos, sino que se les encuentra a lo largo de tres períodos de la secuencia. Significativamente, existen estos sitios en los períodos IV y V. El primero corresponde parcialmente junto con el segundo a la primera fase del período de Integración Cacical (200 a.C. - 800 d.C.). También existieron en el período VI, que corresponde a la segunda fase (800-1500 d.C.) del mismo período, en nuestra nomenclatura.

\section{Guayabo de Turrialba}

El sitio Guayabo de Turrialba, es el complejo monumental arqueológico del país que cuenta con el mayor número de datos cronométricos. Más arriba se mencionó una fecha de radiocarbono (Beta-12345) cuyo rango $(1 \sigma)$ corresponde al lapso 530-390 a.C., tiempo en que se presume 
podrían haberse iniciado las obras constructivas en el sector central del sitio. Dado su origen en restos de carbón vegetal encontrados en la base del Montículo Principal, parece anteceder la etapa constructiva de esta estructura.

Otra fecha de radiocarbono (LSU-70-173) marca el rango 712-1194 d.C., Se le considera aplicable a una etapa ocupacional del sitio, en general, pues no se cuenta con datos acerca de un contexto específico (Aguilar, 1972). El lapso coincide con tiempos entre los siglos VIII al XII, en la primera fase del período de Integración Cacical. Al parecer, proviene de la excavación de una cala excavada en alguna de las estructuras, de manera que correspondería a una etapa constructiva de los rasgos monumentales.

Más precisas, en cuanto al contexto en que las muestras fueron recolectadas, son otras cuatro fechas de radiocarbono, cuyo rango conjunto $(1 \sigma)$ cubre el lapso entre los años 815 y 1340 d.C., coincidente con la última fase ocupacional del sitio Guayabo. Todas estas fechas provienen de muestras asociadas directamente con rasgos arquitectónicos del sector NW del sitio (Hurtado de Mendoza \& Gómez, 1985) y son interpretadas como controles cronométricos de la etapa ocupacional tardía del mencionado sector. La tabla que sigue muestra en detalle los datos de estas cuatro determinaciones de fechas.

\section{Fechas ${ }_{14} \mathrm{C}$ del Sector NW, Monumento Nacional Guayabo}

\begin{tabular}{|c|c|c|c|}
\hline Muestra & $\begin{array}{c}\text { Fecha } \\
\text { Calendario }\end{array}$ & Rango (1б) & Contexto Cultural \\
\hline SI-6587 & $880 \pm 65$ d.C. & 815-945 d.C. & $\begin{array}{l}\text { Fondo de pozo de control del nivel freático, Plaza Palomo. } \\
\text { Nivel 8, estéril. Niveles 1-6 cerámica: } 70 \text { a } 86 \% \text { La Cabaña; } \\
14 \text { a 30\% La Selva-El Bosque. }\end{array}$ \\
\hline SI-6590 & $1015 \pm 65$ d.C. & 950-1080 d.C. & $\begin{array}{l}\text { Cala } 90 \mathrm{~m} \text { Oeste del punto de origen alfa }(\alpha) \text {. Relleno de } \\
\text { montículo. Cerámica: } 53 \% \text { La Cabaña; } 41 \% \text { La Selva }\end{array}$ \\
\hline SI-6586 & $1175 \pm 75$ d.C. & $1100-1250$ d.C. & \multirow{2}{*}{$\begin{array}{l}\text { Plaza Palomo, terraplén del complejo habitacional en sector } \\
\text { NW. Cerámica La Cabaña predominante. }\end{array}$} \\
\hline SI-6589 & $1285 \pm 55$ d.C. & 1230-1340 d.C. & \\
\hline
\end{tabular}

La complejidad arquitectónica de Guayabo es excepcional, solamente comparable con la que se intuye para el caso del sitio Cutris. Un inventario de rasgos arquitectónicos basado en el plano publicado por Fonseca (1979) da cuenta de 43 montículos y basamentos, 3 acueductos y 2 tanques, 3 pozos de drenaje, 2 plazas, 7 calzadas internas y 2 externas, y 4 plataformas (Hurtado de Mendoza \& Gómez, 1985). Sin embargo, ha sido motivo de constante insistencia por parte nuestra que tal complejidad no debe ser considerada como el resultado de un evento constructivo de corta duración ni planificado de una sola vez ni en forma integral, sino como un largo proceso de etapas constructivas paulatinas y sectorizadas, según se vislumbran en los resultados de los análisis presentados en la sección anterior.

Los datos de otros sitios monumentales de las vertientes y llanuras del Atlántico, que a continuación se discuten, no hacen sino destacar la mencionada naturaleza excepcional de Guayabo y Cutris, frente a sitios que, en general, son de menor dimensión. También, se hace evidente que la temporalidad de los sitios monumentales no es, en absoluto, exclusiva de la fase más tardía de la secuencia cultural prehispánica; y que el estilo y diseño arquitectónico de estos 
sitios no revela monotonía sino que, por el contrario, muestra una notable variabilidad en formas y tamaños.

\section{Severo Ledesma}

Este es otro sitio monumental, que cuenta con fechas de radiocarbono. El sitio es descrito por Snarskis $(1978$; 1984) como los restos estructurales de "una forma muy diferente a los de los sitios tardíos como Las Mercedes y Guayabo". Se refiere a lo que parecen ser los basamentos de dos estructuras cuadrangulares construidas con bloques redondeados. Una de estas estructuras tiene $25 \times 15$ metros y otra mide $12 \times 3.5$ metros.

Ninguna de estas estructuras cuenta con mampostería que exceda de una hilada, pero muestran profusión de bloques dentro del área delimitada por las "paredes". Contienen rasgos funerarios, lo cual no implica que no cumplieran también la función habitacional que sugiere el investigador.

Hay tres fechas de radiocarbono (UCLA-2175-D; UCLA-2175-C; I-7514) que definen conjuntamente el rango ocupacional $(1 \sigma)$ de la primera estructura, entre el año 140 a.C. y el 510 d.C., tiempos que corresponden a la primera fase (200 a.C.-800 d.C.) del período de Integración Cacical. Severo Ledesma es un sitio multicomponente, pero los informes de Snarskis enfatizan la asociación de las tumbas y rasgos con materiales El Bosque, solamente.

\section{Nájera}

Kennedy (1968) observó en este sitio montículos, pisos empedrados y una "inusual plaza circular definida con un reborde" (Snarskis, 1984). Este sitio es también conocido como "Alto Varas". Kennedy lo catalogó como multicomponente, con ocupación en tres períodos, desde el año 300 a.C. hasta el 1400 d.C., pero la clasificación de una pequeña colección de tiestos por investigadores del Museo Nacional (Vázquez, Massey \& Sánchez, 2002), reveló que el 100\% de la cerámica es del complejo La Cabaña, lo cual ubica al sitio en la fase más tardía de la secuencia. Una visita nuestra al sitio en Febrero del 2005, corrobora esta información, tanto en el sitio como en otras localidades vecinas.

\section{La Zoila}

Las observaciones más recientes de este sitio (Vázquez, 2002) dan cuenta de cinco cementerios, cuatro montículos, algunos segmentos de calzadas y áreas pequeñas empedradas. También La Zoila parece ser el destino de la Calzada Alto Varas (Vázquez, Massey y Sánchez, 2002), una prolongación de la Calzada Caragra que tiene su origen en Guayabo de Turrialba.

El sitio La Zoila es multicomponente, según lo denota la presencia de cerámica El Bosque, La Selva y La Cabaña, pero no se cuenta con datos cuantificados de estos componentes. Si se apela a las cifras de los sitios Azul y La Isabel, inmediatamente vecinos, se nota que la cerámica El Bosque oscila entre 40 y $50 \%$ de las colecciones; la cerámica La Selva se confina entre el 38 y 40\%; y la cerámica La Cabaña aparece en proporciones menores, del 5 al 21\%. Estas cifras 
tienden a ubicar la etapa de mayor ocupación en la primera fase (200 a.C.-800 d.C.) del período de Integración Cacical, con modesta pero no insignificante sobrevivencia en la fase tardía (8001500 d.C.) del mismo período.

\section{Las Mercedes}

Las prospecciones realizadas en la Finca Las Mercedes (Gutiérrez y Hurtado de Mendoza, 1986) revelaron una complejidad arquitectónica sustancialmente mayor que la ilustrada por su descubridor en el siglo XIX (Hartman, 1901). También se hizo evidente en esta ocasión que existen sectores del sitio que son multicomponentes, denotando una historia ocupacional más antigua de la que se le ha asignado en forma habitual, principalmente por la impresión resultante del hallazgo en el sitio de algunos materiales culturales de tiempos del Contacto.

Vista en una dimensión amplia, sub-regional, la finca Las Mercedes muestra varios sectores separados entre sí, que cuentan con monumentalidad, como sigue:

Las Mercedes Sur (Sectores A, B, C, D, E, F). Muestran un petroglifo de gran tamaño, dos amplias plataformas definidas por muros de contención, sobre las que se aprecian dos conjuntos de montículos. En uno se contó cuatro montículos circulares, dos de los cuales pasan de los 15 metros de diámetro. En otro conjunto de montículos destaca uno de 3 metros de altura y 30 metros de diámetro. Se observó lo que parece ser el piso empedrado de una plaza. La cerámica recolectada en el Sector B está proporcionalmente dominada por el complejo El Bosque (85$100 \%)$, mientras que la del Sector E se reparte entre La Montaña (1.4\%), El Bosque (54.1\%) y La Selva (44.4\%). En esta parte del sitio Las Mercedes, no se ha encontrado cerámica del complejo La Cabaña, haciendo manifiesta y enfática la correlación de los rasgos monumentales enumerados con la primera fase del Período de Integración Cacical (200 a.C.-800 d.C.).

Las Mercedes Norte (Sectores O, P, Q). No muestra mucha monumentalidad en superficie, destacando un "palenque" o "alzado" indefinido; y dos montículos de apreciable tamaño en el Sector Q, donde existieron tres amplios cementerios. La cerámica de esta sección Norte de Las Mercedes es casi exclusivamente (98.5 al 100\%) del complejo El Bosque. Así, una vez más se hace evidente la correlación de estructuras monumentales con la primera fase del Período de Integración Cacical. No se encontró cerámica tardía La Cabaña.

Las Mercedes Centro (Sectores K, L, M, M-1, N). Corresponden al complejo arquitectónico ilustrado por Hartman, ampliado hacia sectores vecinos que también muestran estructuras en dos conjuntos relacionados. En el primero está el "sitio de Hartman" con montículos de gran tamaño $\mathrm{y}$ anchos muros, muy afectados por los intentos para nivelar el terreno con tractores. En el otro conjunto se aprecian cuatro montículos y segmentos de otro cuya medición reveló un diámetro de 28 metros. Hay otros montículos aislados. La cerámica analizada proveniente de esta sección central, incluye materiales del complejo La Cabaña, en proporciones entre 24 y $36 \%$ del total. La cerámica El Bosque varía entre cifras del 47 al 99\%; mientras que la cerámica La Selva se presenta en proporciones del 15 al 68\%. En suma, estas cifras ilustran la naturaleza multicomponente del sitio Las Mercedes en su sector nuclear, no siendo el componente tardío el mayoritario. 


\section{Anita Grande y Finca Costa Rica}

Estos dos sitios monumentales fueron estudiados por Alanson Skinner en los años 1916 y 1917 (Lothrop, 1926). Son relativamente pequeños, pero en el primero se registró un montículo y dos en el segundo. Al igual que ocurre con Las Mercedes, con base en la monumentalidad, se les considera como asentamientos de la fase más tardía o Período VI de la secuencia cultural (cf. Snarskis, 1984), pero la evidencia para tal aseveración es precaria.

\section{La Cabaña}

Este sitio consiste de tres estructuras circulares que han sido interpretadas como "pisos de casas" debido a la presencia de fogones y piedras de moler. Dos de estos basamentos, los de mayor diámetro (13 y 15 metros) están muy juntos; el tercero, de 10 metros de diámetro está apartado de los anteriores y separado por una plaza cuadrangular, cuyo perímetro está empedrado y conecta con una amplia calzada, de 4-5 metros de ancho, también empedrada y que se dirige hacia el Oeste.

El sitio La Cabaña ha sido adscrito al Período VI (1000-1550 d.C.), principalmente bajo el criterio de que los sitios complejos, con arquitectura monumental, representan una situación de "guerra y balcanización" que caracteriza a este período tardío (Snarskis, 1984). Sin embargo, los dos controles cronométricos que han sido obtenidos para este sitio definen fechas ${ }_{14} \mathrm{C}$

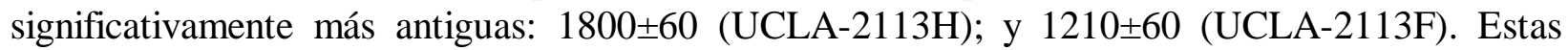
dos fechas fueron logradas a partir de muestras obtenidas de tumbas tipo corredor y ambas están

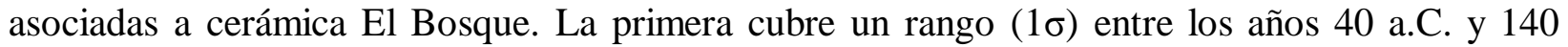
d.C.; la segunda, entre 680 y 800 d.C., revelando un lapso más consecuente con los períodos IV y V de la secuencia centroamericana.

En la nomenclatura que preferimos para la cuenca caribeña de Costa Rica, las fechas mencionadas cubren adecuadamente la duración temporal de la primera fase (200 a.C.-800 d.C.) del período de Integración Cacical, caracterizado por las cerámicas El Bosque y La Selva. No encontramos inconformidad en las fechas de radiocarbono y consideramos que el sitio La Cabaña, al igual que Las Mercedes y otros sitios monumentales, constituyen evidencia de que la monumentalidad arqueológica en Costa Rica no es un fenómeno exclusivo del Período VI y que tiene antecedentes importantes en épocas mucho más antiguas (Períodos IV y V).

\section{Williamsburg}

Este sitio también constituye un ejemplo de monumentalidad en tiempos anteriores al Período VI. Fue estudiado originalmente por Hartman (1901), principalmente como sitio funerario; y después por Stirling $(1969 ; 1997)$, quien lo describe como "un grupo de montículos con paredes de piedra". La única fecha que obtuvo Stirling provino de una de las cuatro tumbas que excavó en uno de los montículos, el cual describe como de "10 metros de diámetro y $91 \mathrm{~cm}$ de alto,

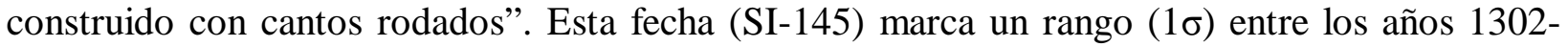
1641. A Stirling no le pareció inesperado el resultado, sino congruente con la supuesta posición 
cronológica tardía de Las Mercedes, un vecino cercano y que produjo cerámica comparable en estilos.

Un examen del informe de Corrales y Gutiérrez (1986) sugiere que pudiera ser el montículo M-6, en la nomenclatura de estos investigadores, el que excavó Stirling, pues es el que mejor se ciñe al diámetro indicado. Todos los demás montículos del sitio tienen dimensiones mayores. El montículo M-8 es el más grande, con un diámetro de 35 metros y una altura de 1.50 metros.

A nivel general, la cerámica recuperada y analizada por Corrales y Gutiérrez, corresponde en la mayor proporción a materiales La Selva (64\%), seguida por La Cabaña (23\%) y por El Bosque (9\%). Estas cifras exponen la calidad multicomponente del sitio Williamsburg, pero no necesariamente la ubicación temporal específica de las estructuras. Sin embargo, se debe destacar entre los resultados de Corrales y Gutiérrez, que el área de cementerio del sitio, del cual dicen "que se extiende tanto al Norte como al Sur", muy huaqueado, produjo cerámica El Bosque (21\%) y La Selva (79\%), sin vestigios de materiales del complejo tardío La Cabaña.

Estos resultados, más la fecha ${ }_{14} \mathrm{C}$ obtenida por Stirling, motivaron a Corrales y Gutiérrez (1986:30) para proponer que "la construcción de los rasgos se inició en tiempos de la Fase La Selva (500-900 d.C.), en la cual se dio la mayor ocupación del sitio" y "continuó siendo habitado hasta la parte tardía de la fase La Cabaña (900-1500 d.C.)". Posteriormente, hubo oportunidad de corroborar esta conclusión mediante un análisis de distribución horizontal de la cerámica del sitio (Hurtado de Mendoza, 2002a).

En esta nueva ocasión se hizo notoria una secuencia cronológica relativa en la que se habrían desarrollado las construcciones por grupos de estructuras, discernibles por la proximidad física de sus rasgos componentes y por la evidente separación de cada grupo respecto de los otros grupos. Así, el Grupo Sur compuesto por los montículos M-8, M-9 y M-10, los más grandes del sitio, aparece como el más antiguo, con proporciones relativamente importantes de cerámica El Bosque y altas frecuencias de La Selva. El Grupo Norte, conformado por los montículos M-1, M-2, M3, M-4 y M-5, conectados por calzadas, sigue en la secuencia, pues se reduce la presencia de El Bosque y continúa siendo enfática la proporción de cerámica La Selva.

En ninguno de los tres grupos deja de haber presencia de la cerámica La Cabaña, pero es relativamente más evidente en el Grupo Oeste, formado por los montículos M-6 y M-7. Si la fecha ${ }_{14} \mathrm{C}$ de Stirling procediera efectivamente del M-6, se explicaría su posición tardía en la secuencia, caracterizada por estructuras relativamente menores y sin rasgos accesorios. En suma, la mayor monumentalidad y complejidad arquitectónica de Williamsburg correspondería a los períodos IV y V, en tiempos de la primera fase del período de Integración Cacical. La segunda fase, sin ser insignificante, fue comparativamente modesta.

\section{Ta'Lari de Pacuare}

Este sitio, ubicado en la cuenca media del río Pacuare (Hurtado de Mendoza \& Gómez, 1985) no ha sido estudiado en toda su extensión, pero ha revelado un complejo arquitectónico que incluye amplias terrazas con muros de contención, una plaza delimitada por estructuras elevadas y con muros, segmentos de pisos o calzadas empedradas y nueve montículos de forma circular. El más 
grande de estos, tiene un diámetro de 30 metros y alcanza una altura de 3 metros y, al igual que el M-1 de Guayabo, cuenta con dos escalinatas de acceso en puntos opuestos de la estructura.

Ta'Lari es un sitio multicomponente, con proporciones mínimas de cerámica La Montaña. En cambio, los materiales El Bosque y La Selva son abundantes; y aún más los del complejo La Cabaña. Dado que este patrón es consistente en todas las unidades de recolección que se establecieron en el sitio, tanto de superficie como excavaciones, se considera que este sitio, a diferencia de Guayabo, tuvo su época de mayor desarrollo durante la fase más tardía de la secuencia.

\section{El Escobal}

Ubicado también en la cuenca del Pacuare, este sitio fue registrado por Anayensy Herrera en 1995. En una visita reciente, hecha por arqueólogos del Instituto Costarricense de Electricidad, a raíz de la posibilidad de desarrollar un proyecto hidroeléctrico en el río Pacuare (Hurtado de Mendoza, 2005a), se observó un complejo arquitectónico que incluye montículos, terraplenes de acceso a sectores definidos por muros de contención y plataformas, muros que separan sectores construidos, y un área de cementerio muy perturbada. Las observaciones realizadas sugieren preponderancia relativa de la cerámica La Selva, muy poca presencia de El Bosque; y una menor proporción de cerámica La Cabaña. Esta última, es de tipos propios de la fracción más temprana de la fase La Cabaña (Hernández, c.p.).

En forma preliminar se puede colegir que el sitio El Escobal tuvo un desarrollo paralelo al de Guayabo de Turrialba, con una etapa principal de construcciones durante la primera fase (200 a.C.-800 d.C.) del período de Integración Cacical. La ocupación continuó durante la segunda fase del mismo período, pero se habría interrumpido algunos siglos antes del Contacto.

\section{Rangalle}

Ubicado en la ribera Oeste de la Quebrada Doroy, en la Reserva Indígena Telire (Hurtado de Mendoza, 1986), destaca por la presencia de dos montículos relativamente pequeños, con diámetros de 6 y 8 metros, respectivamente. La aparente modestia de estos rasgos, sin embargo, contradice la magnitud de tres largas paredes de contención, construidas con grandes piedras de río, que interrumpen la pendiente del terreno por el sector Oeste del sitio, formando amplios terraplenes de más de 60 metros de largo por 10 a 12 metros de ancho. La muestra cerámica que se recolectó de la superficie del sitio y de algunos presuntos pozos de huaqueo, contiene proporciones equitativas de materiales Aguas Buenas (Período V) y Chiriquí (Período VI).

\section{Aguacaliente de Cartago}

El informe más reciente de este sitio (Valerio, Solís y Solís, 1986) lo tipifica como un complejo en el cual existe un área funeraria y otra aparentemente habitacional. Este segundo sector cuenta con estructuras de varios tipos, destacando un grupo de ocho montículos y basamentos, y lo que podrían ser patios y calzadas empedradas. Los investigadores muestran cautela al asignar el sitio a alguna fase o período específico, por la presunta contradicción entre la presencia de cerámica del complejo Curridabat (Período V) y la habitual suposición de que sitios de este tipo 
corresponden automáticamente a tiempos tardíos La Cabaña (Período VI). Aún así, concluyen en que la ocupación del sitio se habría extendido "entre aproximadamente el año 300 a.C. y la conquista, siendo su ocupación más densa entre 800 y 1500 d.C.”.

\section{Cutris}

El estudio de este sitio monumental (Guerrero \& Troyo, 1979) indica que el área nuclear en donde se concentran las estructuras, "más de setenta", podría tener unas 15 hectáreas. Los rasgos arquitectónicos identificados son: plataformas, montículos, plazas, caminos y cementerios. Los montículos tienen muros de contención construidos con bloques redondeados de piedra seleccionados por su tamaño y forma ovoide-aplanada. Las estructuras varían entre 0.5 a 2.0 metros de altura y diámetros de 10 hasta 35 metros.

Los investigadores informan acerca de una modalidad peculiar para resolver el acceso a los montículos, pues en vez de que el tramo de escaleras esté ubicado como cuerpo estructural externo, adicional; en Cutris se le incorpora a la estructura misma del montículo, lo cual evita que se ocupe un espacio complementario. También es peculiar el diseño de las calzadas que, en forma conspicua salen radialmente del centro del sitio hacia diversas direcciones. En vez de ser las conocidas vías empedradas, como las de Guayabo por ejemplo, en Cutris las calzadas se definen como amplias excavaciones que tienden a nivelar el terreno y definirlo, lateralmente y por ambos lados, con la acumulación de la tierra extraída del corte. Estas calzadas, que se extienden por kilómetros hacia la periferia, varían en ancho entre 4 y 7 metros, pero en las cercanía del sitio se amplían ostensiblemente para convertirse en anchas avenidas.

La cerámica de Cutris es de naturaleza y aspecto diferentes a la cerámica de las regiones vecinas, de manera que está siendo identificada como una serie local de complejos, cuya secuencia cronológica se extiende por tres fases culturales, desde el año 200 a.C. hasta el 1500 d.C.. Los investigadores sugieren que la fase ocupacional en la cual ocurrió la construcción monumental es la más tardía, que denominan Venecia y que ubican en el lapso del 900 al 1500 d.C. Sin embargo, un análisis reciente de la colección cerámica indica la presencia no despreciable de materiales cerámicos mucho más antiguos, lo cual podría llevar a un replanteamiento del tiempo y duración de la etapa constructiva.

\section{Cubujuquí}

El informe de Gutiérrez \& Mora (1988) da cuenta de un complejo arquitectónico que incluye grupos de montículos, calzadas, una plaza central cuadrangular y dos avenidas flanqueadas por muros que se interrumpen en puntos equidistantes, aparentemente para facilitar el paso hacia las avenidas o para salir de ellas. Los montículos se aglutinan en cuatro grupos separados entre sí, todos conectados por las avenidas, lo cual asigna la impresión de integralidad funcional al sitio. La calzada externa que se proyecta hacia el Norte-Noreste está empedrada, excepto en un tramo alejado unos 80 metros de la plaza. Aquí, la calzada está flanqueada por dos pares de estructuras circulares más pequeñas. El acceso a los montículos más grandes fue resuelto mediante escalinatas construidas con el mismo tipo de piedra utilizado para los muros de contención de los 
montículos mismos. Aún cuando la superficie de las avenidas no está empedrada, se observan sectores alrededor de algunos montículos que sugieren la presencia de pisos empedrados.

Se deduce que el sitio fue estudiado como una sola unidad arquitectónica. No se hizo esfuerzos por determinar la ubicación de los pozos de sondeo respecto de los rasgos individuales. Sin embargo, los resultados del análisis de la cerámica recuperada expuestos por las investigadoras, sugieren una clara dicotomía entre los pozos que produjeron únicamente cerámica tardía (La Cabaña-Cartago); y otros con materiales más antiguos (Curridabat-La Selva, 6-48\%) además de los tardíos (48-94\%). Un indicio adicional de sectorización temporal del sitio lo ofrecen las muestras cerámicas recuperadas, con tamaños ostensiblemente diferentes en los dos grupos de pozos: un promedio por pozo de 7.4 especímenes en el primer grupo, unicomponente (tardío); contra 20.1 especímenes en el grupo bi-componente (temprano).

Las investigadoras, proponen un lapso ocupacional desde el siglo $\mathrm{X}$ hasta "por lo menos dos siglos antes de la conquista española." Sin embargo, la presencia de restos cerámicos Curridabat y La Selva atestiguan una ocupación anterior cuantitativamente significativa.

\section{Sarapiquís}

Descrito como un complejo funerario, este sitio presenta rasgos monumentales, incluyendo por lo menos un montículo y pisos empedrados. La ficha de registro del sitio en el Museo Nacional de Costa Rica, indica que tuvo ocupación durante los períodos Bicromo en Zonas (Período IV) y Policromo Medio (Período V tardío y Período VI temprano). El mismo registro indica un lapso temporal entre los años 500 a.C. y 1550 d.C., seguramente reflejando los resultados del estudio de Herrera (2000).

\section{Crucero}

Este sitio fue encontrado en la ruta y aparente destino de una de las calzadas radiales del sitio Cutris (Guerrero y Troyo, 1997), de manera que parece pertenecer a su ámbito de influencia. El plano que elaboraron los investigadores muestra un terreno de unas cuatro hectáreas en donde se encontró los restos de unos cinco montículos circulares, destacando dos de ellos por su tamaño y por las numerosas huellas de excavaciones ilícitas. El registro del Museo Nacional de Costa Rica lo describe como sitio multicomponente, con ocupación desde el año 500 a.C. hasta el 1550 d.C.

\section{Veracruz}

Este es otro sitio monumental que pertenece al sistema regional de Cutris, siendo el destino aparente de la "Calzada B" que sale de Cutris y se dirige hacia el Noreste (Guerrero y Troyo, 1997). El plano del sitio muestra 10 montículos circulares dispersos en un terreno de unas 6 hectáreas, ubicado en la ribera izquierda del río Toro, a unos $3 \mathrm{Km}$. al Este de Pital. El registro del Museo Nacional de Costa Rica, indica que se trata de un sitio multicomponente que sostuvo ocupación desde el año 500 a.C. hasta el 1550 d.C. 


\section{Bolaños}

El sitio está ubicado en la llamada "Península" que compromete la comarca de Pangola, definida por el curso más bajo del Río Cuarto, antes de su unión con el Río Toro, afluente mayor del río Sarapiquí. Fue estudiado por Mathew Stirling quien destaca la presencia de dos montículos, uno de "tierra negra" de $1.20 \mathrm{~m}$ de alto y $18.3 \mathrm{~m}$ de diámetro; y otro "de piedras de buen tamaño" (Stirling \& Stirling, 1997). La descripción de la muestra cerámica proveniente del primer montículo, sugiere que el sitio es bi-componente, con vasijas trípodes que muestran resemblanza con la cerámica Curridabat y otros materiales que parecen corresponder con los complejos locales Ujarrás y La Isla, de manera que su posición cronológica abarca los períodos V y VI.

\section{Paisajes construidos y evolución del poder en Guayabo}

La discusión acerca de este tema central está fundamentado en las conclusiones que han surgido de la revisión, en las secciones anteriores, de los datos e informaciones disponibles acerca de: 1) la teoría del poder en el nivel de integración cacical de las sociedades prehispánicas; 2) la historia cultural del Monumento Nacional Guayabo y la región de Turrialba; y 3) la cronología y características de la monumentalidad y de la complejidad arquitectónica en los sitios arqueológicos de la cuenca del Caribe en Costa Rica. Destacan las siguientes conclusiones.

En la teoría del poder en cacicazgos:

- Es una sociedad demográficamente más densa que la sociedad tribal.

- Es redistributiva y requiere de centros de coordinación económica, social, política y religiosa.

- Denota la habilidad del cacique para planificar, organizar y desplegar fuerza de trabajo.

- Alienta los excedentes de producción y la especialización del trabajo.

- Muestra mayor sedentarismo.

- Como nivel de integración sociopolítica, no es una categoría homogénea ni permanente sino susceptible de cambio y de expresión en diversos tipos o sub-categorías.

- No depende para su transformación de alguna tecnología innovativa, sino de la intensificación y organización de lo ya conocido para generar excedentes y administrarlos.

- Tiene centros administrativos que no implican urbanización ni nucleización demográfica sino que se limitan al lugar de vivienda del cacique, su familia y allegados, con la mayoría de la población habitando en asentamientos periféricos ampliamente distribuidos en el territorio.

- La vivienda del cacique revela diferenciación en el consumo y denota el nivel enaltecido de su prestigio, rango y poder, incluso santidad.

- Las instancias de conflicto y guerra, aún cuando podrían suscitarse por la necesidad de control y protección del territorio y de rutas de intercambio, son más comunes como formas de violencia política focalizada en los caciques y sus lugares de vivienda. 
- El conflicto revela el carácter perecible de los cacicazgos, cuando encuentran límite a su capacidad de expansión, organización e integración.

Acerca de la historia cultural del sitio arqueológico Guayabo:

- El sitio arqueológico Guayabo es multicomponente.

- Su historia cultural se remonta al período Formativo Medio, pero su monumentalidad corresponde a las dos fases del período de Integración Cacical (200 a.C.-1500 d.C.).

- Los análisis de la distribución relativa de los restos cerámicos de cuatro complejos marcadores de fases ocupacionales, apoyados por controles cronométricos, revelan un proceso constructivo en etapas, en el cual el centro de gravitación de la ocupación se desplazó paulatinamente en una dirección Sureste-Noroeste.

- La etapa de mayor desarrollo constructivo ocurrió en tiempos de la primera fase (200 a.C.-800 d.C.) del período de Integración Cacical, representado por la mayor monumentalidad del sitio en el Sector Central y por el funcionamiento de un cacicazgo redistributivo (Tipo II-B de Sahlins).

- Hubo una etapa de decaimiento o menor desarrollo de la monumentalidad en tiempos de la segunda fase (800-1300 d.C.), cuando las construcciones no lograron replicar las dimensiones de tiempos anteriores; y el cacicazgo de Guayabo asumió características de radicalismo y absolutismo (Tipo II-A de Sahlins).

- La ocupación de Guayabo, concentrada en su última etapa en el sector NW del sitio, cesó alrededor del final del siglo XIII e inicios del siglo XIV de nuestra era.

La cronología del desarrollo de la monumentalidad:

- Aplicando la nomenclatura de periodificación de la región centroamericana, la monumentalidad en sitios arqueológicos de la cuenca del Caribe costarricense, ocurrió desde principios de nuestra era, tanto en el Período V (500-1000 d.C.) como en el Período VI (1000-1550 d.C.).

- En regiones del interior de la Gran Nicoya, en Costa Rica, hubo monumentalidad en tiempos tardíos del Período IV, pero este fenómeno no continuó en los períodos más recientes.

La dimensión y complejidad arquitectónica:

- La complejidad estructural de los sitios es muy variada, destacando por su excepcional magnitud los sitios Guayabo y Cutris, con más de 40 montículos y basamentos, cada uno de estos.

- Ningún otro sitio adquirió niveles comparables de monumentalidad, siguiendo en segundo rango el sitio Cubujuquí y en tercer rango: Williamsburg, Veracruz, Ta'Lari, Las Mercedes (sector Central) y Agua Caliente.

- La estructura interna de los sitios varía desde simples basamentos de mínima emergencia respecto de la superficie, hasta montículos elevados construidos en varias etapas, terraplenes, escalinatas, muros de contención, pisos y calzadas, tomas de agua, 
acueductos y tanques, puentes, plazas, pozas y canales de drenaje, pozos de observación del nivel freático, estatuaria, esculturas y petroglifos.

Diversidad en el diseño de las estructuras:

- Estructuras circulares, elipsoidales, cuadrangulares.

- Calles y calzadas empedradas o no empedradas, definidas por muros o por acumulaciones de la tierra excavada.

- Plazas circulares o cuadrangulares, con aceras circundantes empedradas o sin aceras.

- Escalinatas adosadas a otras estructuras o incorporadas a las mismas.

- Calzadas excavadas o elevadas o que siguen la superficie del terreno.

- Acueductos abiertos o subterráneos.

- Tanques sencillos y pequeños, o grandes y circundados por paredes.

- Esclusa de brecha restringida o de dique y rebalse.

- Terraplenes o terrazas, con o sin muro de contención.

- Rampas o escalones para resolver desniveles.

Significativamente, una buena proporción de estas diversas características está presente en el Monumento Nacional Guayabo, lo que resultará más evidente al observar los planos y fotografías que se incluyen a continuación. Estos han sido organizados como una serie de conjuntos arquitectónicos o zonas del sitio en donde encontramos afinidades estructurales y de estilo que sugieren unidad funcional y que representan, en cierta forma, la secuencia del proceso constructivo del complejo arquitectónico del sitio Guayabo.

Conjunto arquitectónico 1: Calzada Cargara y entrada principal

Conjunto arquitectónico 2: Plaza 1, grupo de estructuras gemelas, acueducto

Conjunto arquitectónico 3: Sector central

Conjunto arquitectónico 4: Plaza 3 y zona residencial NW

Conjunto arquitectónico 5: Plaza y calzada Palomo, obras hidráulicas 


\section{Conjunto Arquitectónico 1: La calzada Caragra y la entrada principal}

Figura 3

Escalinatas y montículos cuadrangulares en la entrada principal. La viñeta ilustra el conjunto, incluyendo la calzada Caragra
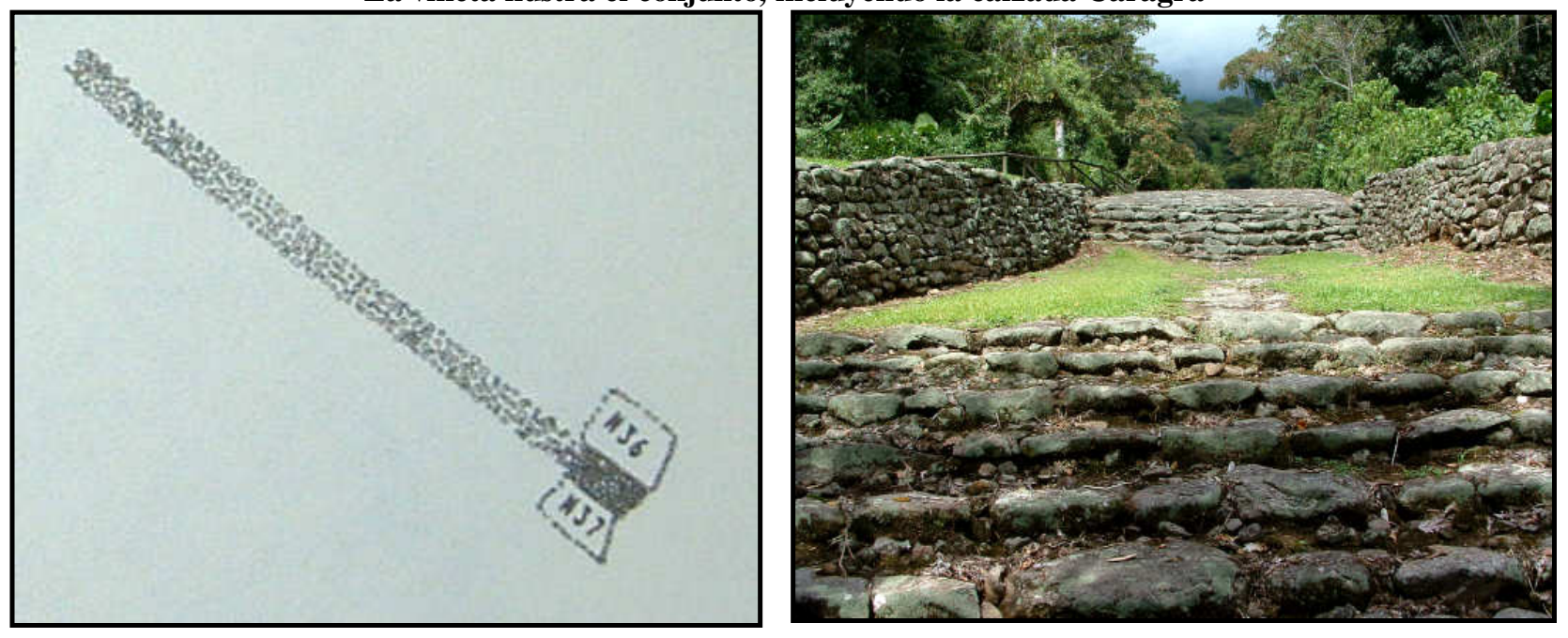

La antigua entrada principal al sitio Guayabo es, notoriamente, la calzada Caragra. Esta viene desde el sitio Guayabo-4, que se encuentra ubicado al Sureste, a una distancia de $1.5 \mathrm{Km}$. Hay indicios de que la calzada Caragra continúa en la misma dirección hasta llegar al sitio Nájera en Alto Varal (Vázquez, Massey y Sánchez, 2002), pero el tramo más inmediato y conocido de 1.5 $\mathrm{Km}$. de longitud, está empedrado y tiene un ancho promedio de casi 7 metros, bastante consistente en toda su longitud.

Se estima que esta calzada requirió de unas 60,000 piedras para su construcción, las que representan un peso de 4200 TM. Al llegar al sitio Guayabo, destacan dos cuerpos de escalinatas y un descanso flanqueado por dos estructuras rectangulares. El primer tramo de escalinata mide en planta 22x7 metros y el segundo mide 2x7 metros (Troyo \& Garnier, 2002). Las dos escalinatas requirieron unas 960 piedras cuyo peso total es de $68 \mathrm{TM}$.

Las dos estructuras rectangulares ubicadas en la entrada, a uno y otro lado de la calzada, miden 16x8 metros y 1.5 de alto (Troyo \& Garnier 2002), con un volumen de obra civil de $72 \mathrm{~m}^{3}$ cada una. La inversión de piedra como materia prima constructiva para los muros de cada uno estos dos rasgos, es equivalente a 90 TM. Se estima que para la construcción de ambos se utilizó unas 3,000 piedras.

En resumen, este primer conjunto arquitectónico está conformado por un tramo de 1,500 metros de la calzada Caragra, las dos escalinatas y los dos montículos cuadrangulares (M36 y M37). Estas obras se construyeron utilizando unas 63,960 piedras, cuyo peso total se estima en 4,448 TM. Actualmente se necesitarían no menos de 250 vagonetas para trasladar toda esta carga. Una cuadrilla de cuatro trabajadores, encargada de seleccionar, extraer y acarrear desde el río Lajitas 16 de estas piedras (con un peso promedio de $70 \mathrm{Kg}$. cada una), en una jornada de 8 horas 
efectivas de trabajo, requeriría de unos 4,000 días (16,000 días/persona) para completar la tarea. Esta cifra se duplica al vislumbrar una segunda cuadrilla encargada de limpiar y preparar el terreno para colocar las piedras en el lugar y forma deseados. Al nivel salarial vigente para trabajadores de campo, de US\$16.50 por día de trabajo, incluyendo las cargas sociales, se requeriría una inversión de algo más de medio millón de dólares para cubrir la planilla.

Estas cifras debieran ilustrar en cierta forma el significado económico de la capacidad efectiva de los caciques para convocar y conseguir tributos en la modalidad de fuerza de trabajo. También, proporcionan una idea acerca del tiempo que se requeriría para ejecutar la obra: 13 años, con ocho trabajadores. Obviamente, este tiempo se reduciría si se incrementa el contingente: 6.5 años con dieciséis trabajadores; 3.3 años con 32 trabajadores; 1.6 años con 64 trabajadores, y así sucesivamente, siempre que se cuente con el suficiente personal y que sea de tiempo completo, algo bastante improbable.

Por un lado, la población del cacicazgo de Guayabo no parece haber sido muy grande. Nuestras estimaciones para la parcialidad Norte del sistema cacical de Turrialba (Hurtado de Mendoza, 2004) sugieren que alrededor del siglo XII hubo unos 3,000 habitantes (670 familias) en la comarca que está irrigada por los ríos tributarios del Reventazón en su margen izquierda, principalmente los ríos Turrialba, Guayabo, Lajas-Lajitas. Este tamaño de la población, implica que la fuerza de trabajo masculina, potencial, no podría ser más numerosa que la cantidad neta de familias. Por otro lado, se puede suponer que no toda la fuerza potencial de trabajo estaba disponible, por tener que cumplir con otras actividades cotidianas propias, principalmente productivas, además de las actividades relacionadas con sus respectivos caciques.

Dada la impracticabilidad implícita de una estrategia basada en la intensificación del reclutamiento de la fuerza de trabajo, la única otra opción, digna de tenerse en cuenta, es que la ejecución de las obras se extienda en el tiempo. Que no se pretenda llevarlas a cabo de una sola vez y en una sola ocasión, sino en etapas, en forma paulatina y acumulativa. Se han observado indicios de este procedimiento en las estructuras monumentales del sitio Guayabo, las que se ilustrarán en cada caso. Aquí, debemos llamar la atención a la probabilidad de que la calzada Caragra y sus escalinatas no hayan sido objeto de una sola etapa constructiva, sino de varias, principalmente en lo que concierne a su anchura. Suponiendo que los arqueólogos reconstructores de la calzada no habrían desplazado mayormente las piedras que la componen, respecto del lugar donde las encontraron, resulta aparente que la calzada es el resultado de un proceso de ampliaciones de su ancho, en etapas efectuadas bajo normas diferentes de selección de las piedras, principalmente en cuanto al tamaño.

El resultado de tal procedimiento parece ahora distinguible como tres "carriles" longitudinales con tamaños promedio diferentes de las piedras: más grandes en el carril central, menos grandes en los carriles laterales. La fotografía de la Escalinata-B, la tabla de mediciones que le sigue y finalmente un gráfico con los resultados del análisis, ilustran esta situación en forma bastante objetiva. Una situación similar es aparente a lo largo de la calzada misma, pero requiere comprobación. Aquí, solamente se expone este caso específico, con la finalidad de mostrar la plausibilidad de una hipótesis que propone la modalidad constructiva de ciertas obras civiles en Guayabo, aplicando la estrategia de etapas dispersas en el tiempo, con resultados paulatinos y acumulativos. 
Figura 4

La escalinata "B" en la entrada principal, dividida en ocho secciones para determinar el tamaño de las piedras utilizadas en su construcción

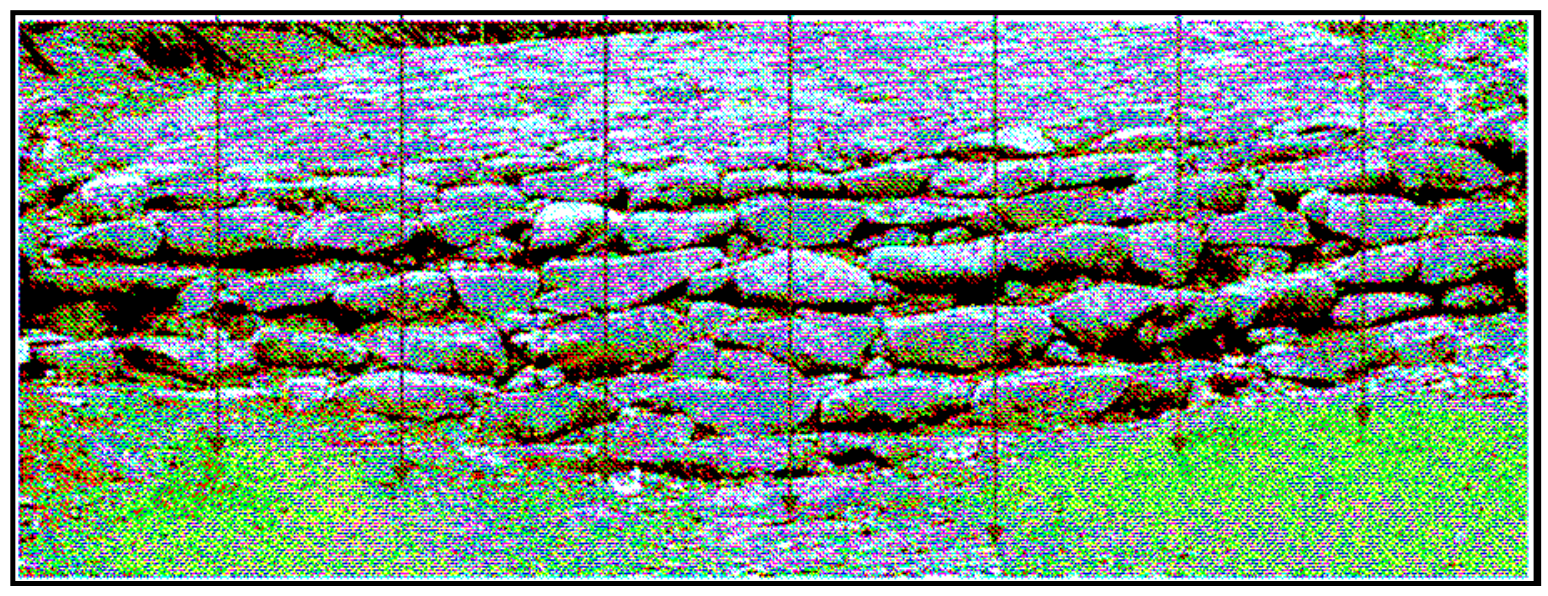

Medición del largo de las piedras de la Escalinata-B $(\mathrm{cm})$ por secciones

\begin{tabular}{|c|c|c|c|c|c|c|c|}
\hline $\begin{array}{c}\text { Sección } \\
1\end{array}$ & Sección 2 & Sección 3 & Sección 4 & Sección 5 & Sección 6 & $\begin{array}{c}\text { Sección } \\
7\end{array}$ & $\begin{array}{c}\text { Sección } \\
8\end{array}$ \\
\hline 25 & 25 & 20 & 25 & 50 & 50 & 25 & 60 \\
\hline 30 & 30 & 20 & 30 & 50 & 60 & 40 & 40 \\
\hline 30 & 50 & 25 & 60 & 50 & 30 & 50 & 50 \\
\hline 40 & 40 & 20 & 60 & 60 & 80 & 30 & 30 \\
\hline 15 & 30 & 30 & 90 & 70 & 70 & 50 & 30 \\
\hline 20 & 40 & 30 & 20 & 70 & & 60 & 50 \\
\hline \multirow[t]{4}{*}{50} & 40 & 60 & 80 & 80 & & 100 & 40 \\
\hline & 20 & 60 & 25 & 70 & & & 30 \\
\hline & & & 100 & 80 & & & \\
\hline & & & 100 & & & & \\
\hline $\begin{array}{c}\text { Promedio } \\
30.0\end{array}$ & $\begin{array}{c}\text { Promedio } \\
34.4\end{array}$ & $\begin{array}{c}\text { Promedio } \\
33.1\end{array}$ & $\begin{array}{l}\text { Promedio } \\
59.0\end{array}$ & $\begin{array}{c}\text { Promedio } \\
64.4\end{array}$ & $\begin{array}{c}\text { Promedio } \\
58.0\end{array}$ & $\begin{array}{c}\text { Promedio } \\
50.7\end{array}$ & $\begin{array}{c}\text { Promedio } \\
41.3\end{array}$ \\
\hline \multicolumn{3}{|c|}{ Carril izquierdo $=2.60$ metros } & \multicolumn{2}{|c|}{$\begin{array}{c}\text { Carril central }=1.75 \\
\text { metros }\end{array}$} & \multicolumn{3}{|c|}{ Carril derecho $=2.60$ metros } \\
\hline
\end{tabular}


Figura 5

Representación gráfica de las variaciones en el tamaño de las piedras, por secciones.

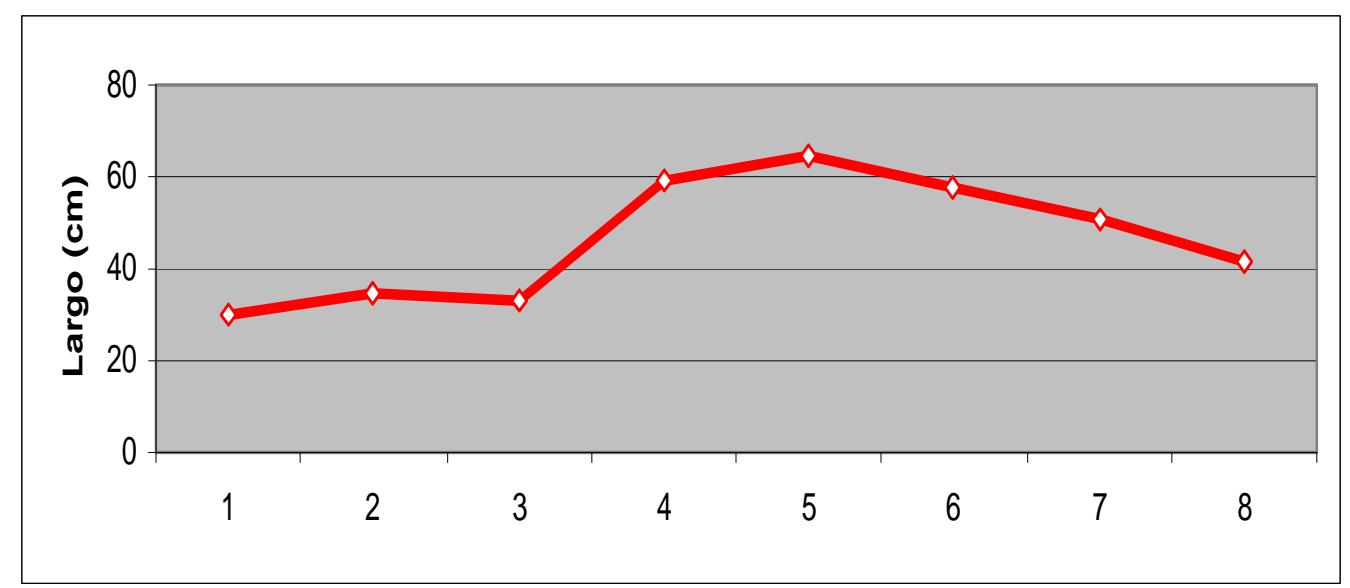

\section{Conjunto Arquitectónico 2: Plaza 1, grupo de estructuras gemelas, acueducto}

Figura 6

Ruinas de las estructuras gemelas, acueducto y calzada estrecha. La viñeta muestra el conjunto, incluyendo la Plaza 1
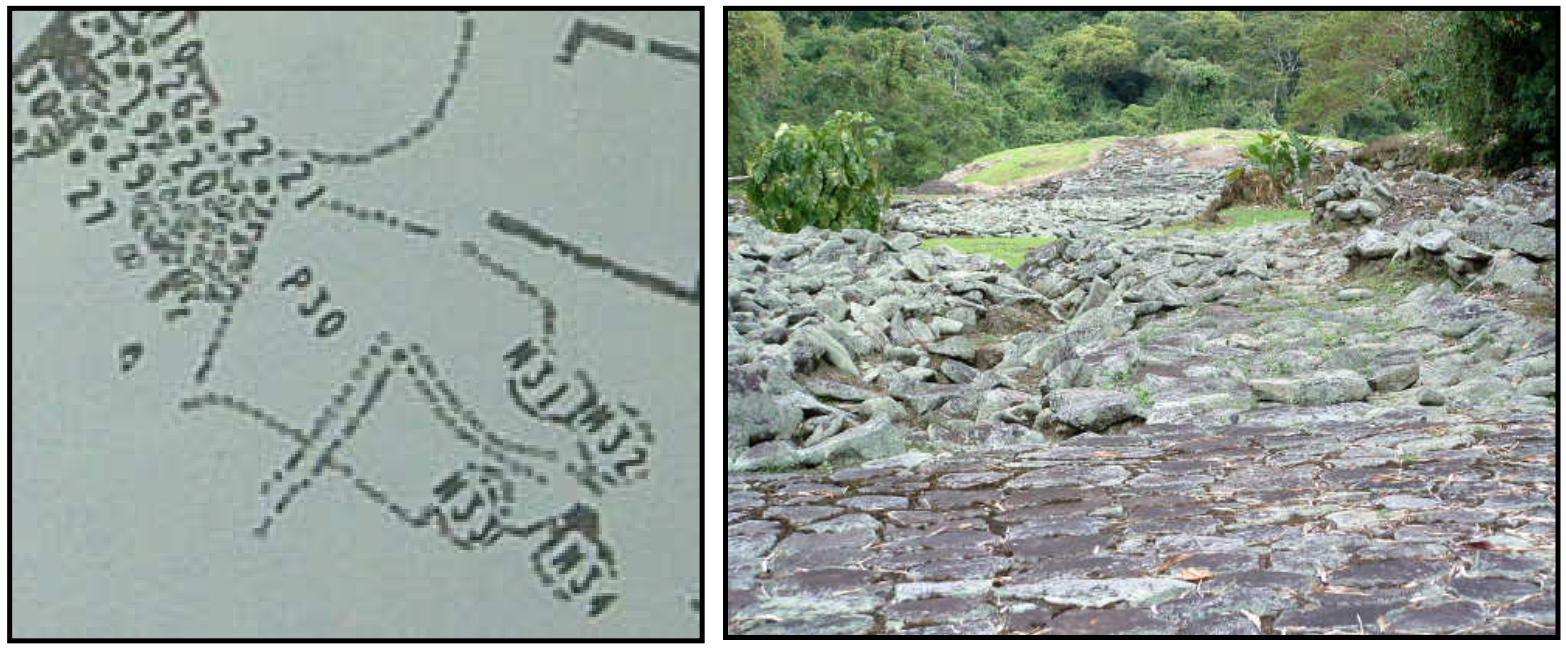

Este conjunto se encuentra en el final de la calzada Caragra, antes de llegar al Montículo Principal. Consta de cuatro estructuras de aparente forma circular, muy derruidas, que se presentan como dos pares de montículos gemelos, entre los cuales continúa la calzada por un tramo ostensiblemente estrecho, que se reduce aún más por la presencia de un canal o zanja que discurre por delante de los montículos M33 y M34. 
Estas dos estructuras y sus contrapartes M31 y M32 tienen dimensiones muy similares, con un diámetro de 9 metros en cada caso (Troyo \& Garnier, 2002:102). Las cantidades de escombros sugieren que no excedían de unos $80 \mathrm{~cm}$ de alto. Así, cada uno representa un volumen de obra de $51 \mathrm{~m}^{3}$ con una inversión de piedra, en muros de contención, de 42.5 TM cada uno. Se intuye que este grupo corresponde a las primeras etapas constructivas del sitio y es evidente que fue respetado por los posteriores constructores de la calzada Caragra y del Sector Central. El grupo de montículos parece cumplir un rol de control de acceso y vinculación con un amplio espacio que se extiende hasta el pie del Montículo Principal.

No todo este espacio pertenece al conjunto arquitectónico 2, pues el sector empedrado del extremo Oeste está nítidamente vinculado con el Montículo Principal del sitio, el cual es parte integrante del conjunto arquitectónico 3. En claro contraste con la plaza empedrada, en el lado Este hay un sector cuadrangular no empedrado, sin duda una plaza bien definida y que posee "veredas" empedradas en algunas partes de su perímetro. Mide unos 3,700 $\mathrm{m}^{2}$. Está orientada en forma armónica, respecto de los cuatro montículos (pares gemelos) arriba descritos, no así con el Montículo Principal o con el Montículo 28. Sin embargo, esta segunda estructura se vincula con la plaza, por la esquina norte de la misma, mediante una escalinata (Ver Troyo y Garnier, 2002: Figura 19).

Finalmente, parece aquí apropiado considerar y evaluar la zanja o canal que pasa por entre el grupo de cuatro montículos, paralela al tramo estrecho de la calzada Caragra. Se sospecha que se trata de un acueducto intencional y no solamente un drenaje. Podría interpretarse como una versión primitiva de las obras hidráulicas más sofisticadas del sector central y del sector Noroeste del sitio. Si así fuera, se estaría agregando plausibilidad a la hipótesis de que el conjunto arquitectónico 2 representa una etapa temprana del proceso constructivo, pues contó con su propio sistema de conducción del agua y funcionó como una unidad arquitectónica armónica, compuesta por montículos, plaza, acueducto y talvez una calzada de acceso de menores dimensiones.

\section{Conjunto Arquitectónico 3: Sector Central}

Figura 7

Montículos M-1, M-28 y plaza principal en el sector central. La viñeta muestra la disposición de las estructuras, en plano.
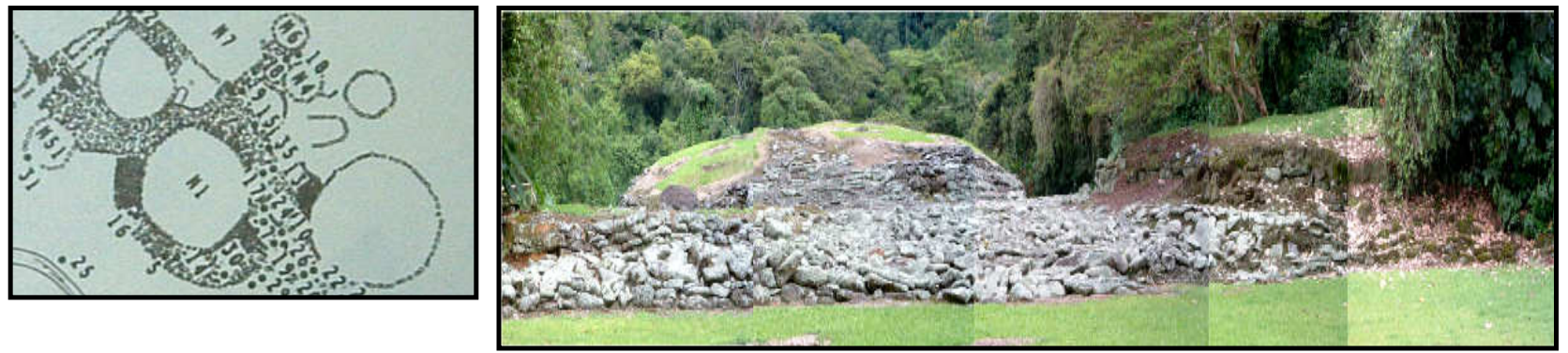

En este conjunto arquitectónico se imponen, por su tamaño y majestuosidad, el Montículo 1 (Principal) y el Montículo 28. La monumentalidad asociada a éstos dos montículos incluye una 
plaza empedrada y una terraza en la cual hay un grupo de tumbas de cajón construidas con lajas. También el Montículo 1 está rodeado por calzadas empedradas de ancho variable, interrumpidas por espacios abiertos no empedrados que pudieron ser plazoletas.

Una de estas plazoletas, de menor tamaño, ubicada exactamente al Norte del Montículo 1, presenta una larga laja a modo de puente, de manera que pudo tratarse de una charca. Complementan el conjunto tres terrazas cuadrangulares distribuidas por ambos costados y por detrás del Montículo 1, sobre los cuales hay basamentos circulares. Como elemento accesorio se observa un canal abierto y tanque de agua que discurre de SW al NE delimitando este conjunto respecto del sector NW. Un puente de lajas muy grandes resuelve el paso por encima del canal desde el Sector Central hacia el Noroeste.

Hay claros indicios de que tanto el Montículo 1 como la calzada que lo rodea son el resultado de varias etapas constructivas. En el caso del Montículo 1, está bien documentada su estructura en cuerpos cilíndricos sobrepuestos, los cuales son consecutivamente de menor diámetro (Troyo \& Garnier, 2002: 109-112). En cuanto a la calzada que circunda al Montículo 1, ya se conoce que no es la primera que se construyó, pues existe por debajo de la misma, a unos $60 \mathrm{~cm}$, otra calzada empedrada de construcción y uso anterior (Hurtado de Mendoza \& Gómez, 1985).

No parece existir duda en cuanto a considerar el Sector Central como expresión de la etapa culminante de desarrollo del sitio y de su monumentalidad. Se intuye que asociados a este clímax de modificación del paisaje están: la calzada Caragra en su mayor anchura y extensión; el sistema hidráulico de canal abierto que delimita el sector por su lado Noroeste; y las terrazas con estructuras menores que rodean al Montículo 1 por tres lados.

Como medida de la dimensión del poder cacical ejercido en la etapa culminante de desarrollo del sitio Guayabo, se pueden citar algunas cifras: Al adquirir su tamaño definitivo, el Montículo Principal (M1) medía 3.55 metros de alto y 30.4 metros de diámetro. La estructura muestra cuatro cuerpos superpuestos y se necesitó unas 12,600 piedras para construir los muros externos. El peso total estimado de las piedras es de unas 872 TM. Conjuntamente, los muros y el material de relleno, representan un volumen de obra civil equivalente a 2,170 $\mathrm{m}^{3}$. En comparación, el Montículo 28, con una altura de 2.80 metros y diámetro de 32 metros, debió requerir unas 14,000 piedras cuyo peso total sería de 844 TM. La obra civil correspondiente fue de $2252 \mathrm{~m}^{3}$.

La extracción de piedras del río Lajitas y su acarreo al lugar de la obra, conjuntamente con la consecución y traslado del material de relleno, en suficientes cantidades y volúmenes para la construcción del Montículo Principal, le llevaría unos 50 años de trabajo a una cuadrilla de 4 trabajadores. Obviamente, ocho trabajadores lo harían en 25 años, 16 trabajadores en 12.5 años, 32 trabajadores en 6.3 años, 64 en 3.1 años; y 128 en año y medio, siempre y cuando estuvieran disponibles a tiempo completo. Y aún estando disponibles, prescribe una norma cacical que éste, cuando recibía tributo en la forma de trabajo, debía ser espléndido y le correspondía alimentar y sosegar la sed de sus tributarios. Imagínese el lector a un cacique urgido porque su montículo se construya en un año y medio, alimentando a 128 cargadores durante 450 días hábiles para contar con las piedras y material de relleno necesarios para la estructura. 
En términos económicos, solamente esta cuadrilla de 4 trabajadores representaría una inversión de 60,000 días/personas de fuerza de trabajo, cuyo costo en salarios en nuestros días sería de casi un millón de dólares de los Estados Unidos. Pero esta suma no cubre todos los costos de la obra. En su cálculo no están incluidos los requerimientos de otros tipos y cantidades de personal laboral, por ejemplo, albañiles, capataces, ingenieros, personal de apoyo para preparar alimentos. Tampoco se está teniendo en cuenta el valor de los materiales de construcción.

Dados estos parámetros, asociados al caso del Montículo Principal, solamente, entonces resulta poco factible y ciertamente impracticable un proyecto de diseño y construcción simultánea de todo el conjunto arquitectónico del Sector Central $\mathrm{y}$, menos aún de todo el complejo arquitectónico del sitio Guayabo. Una vez más, se torna más viable la opción de una estrategia constructiva en etapas, en las cuales se atendía la tarea por partes, cada una de magnitud más manejable en tiempo razonable y acorde con los recursos de mano de obra disponibles.

En este sentido, se podría interpretar la estructura del Montículo Principal, en cuatro cuerpos superpuestos y de diámetro cada vez menor, como el resultado de su construcción en etapas cuyas metas implicaron volúmenes de obra civil y metas parciales más factibles y practicables. La tabla de datos, basada en el trabajo descriptivo de Troyo y Garnier (2002) permite reconstruir las dimensiones de la obra en las cuatro etapas constructivas.

Estimación de piedra utilizada y volumen de obra civil del Montículo Principal

\begin{tabular}{|c|c|c|c|c|c|c|}
\hline Etapas & Perímetro & $\begin{array}{c}\text { Cantidad de } \\
\text { Piedras }\end{array}$ & $\begin{array}{c}\text { Peso } \\
\text { promedio de } \\
\text { piedras }\end{array}$ & Peso total & $\begin{array}{c}\text { Volumen de } \\
\text { Obra Civil } \\
\left(\mathbf{m}^{\mathbf{3}}\right)\end{array}$ & $\begin{array}{c}\text { Volumen } \\
\text { Acumulativo } \\
\left(\mathbf{m}^{\mathbf{3}}\right)\end{array}$ \\
\hline 1 & 95.5 & 3,820 & 70.4 & 268,928 & 268.9 & 268.9 \\
\hline 2 & 92.4 & 4,618 & 70.4 & 325,107 & 325.1 & 594.0 \\
\hline 3 & 86.1 & 2,582 & 70.4 & 181,801 & 181.8 & 775.8 \\
\hline 4 & 79.8 & 1,596 & 60.0 & 95,760 & 95.8 & 871.6 \\
\hline
\end{tabular}




\section{Conjunto Arquitectónico 4: Plaza 3 y zona residencial NW}

Figura 8

Basamentos circulares en la zona residencial del NW. La viñeta ilustra la distribución de estructuras, en plano
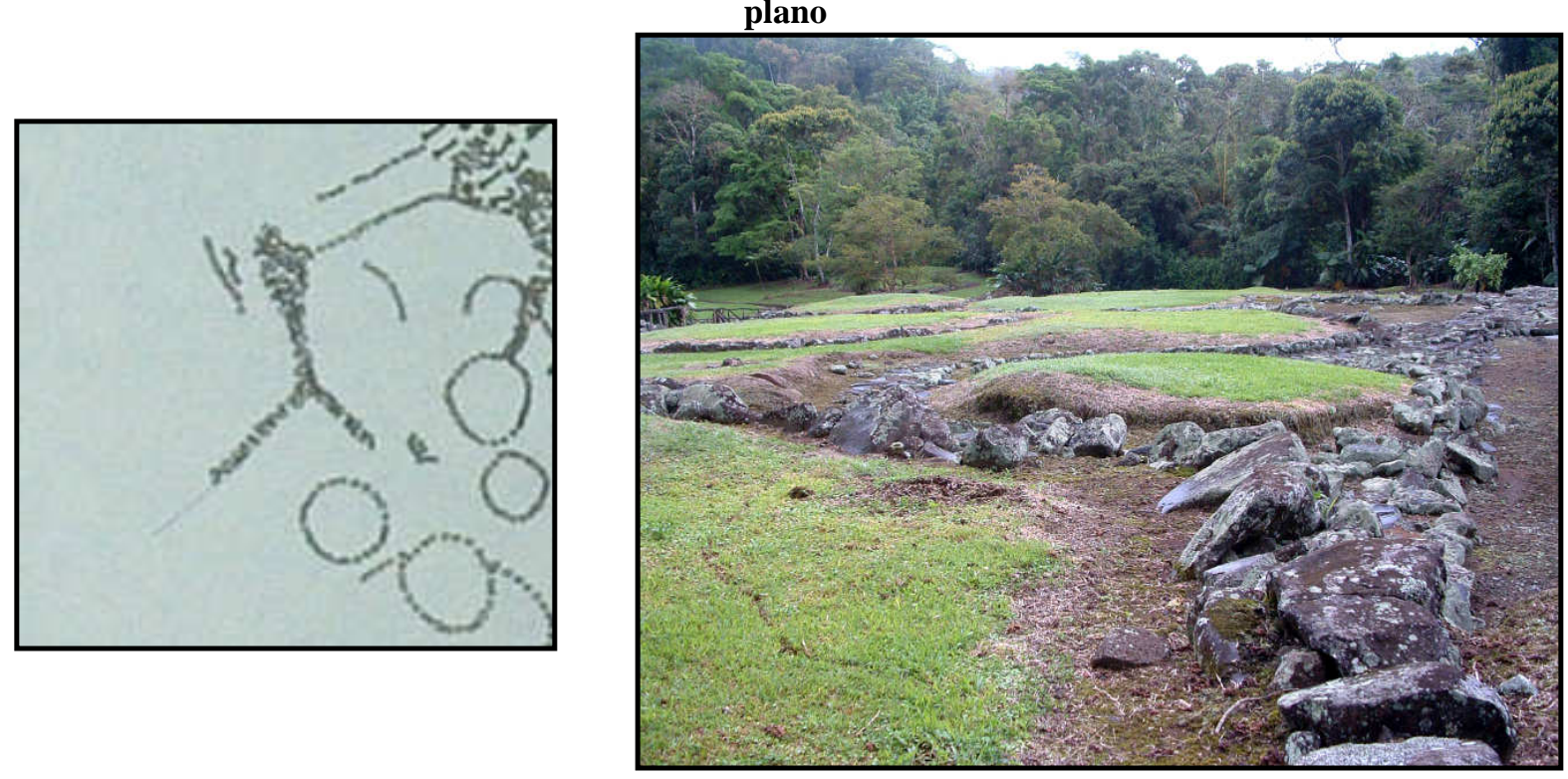

Una característica principal de este conjunto arquitectónico es que está construido encima de una amplia terraza, definida por un muro de contención en el cual de utilizaron bloques de piedra excepcionalmente grandes, juntamente con otros de tamaños menores. El muro de contención que define el área por el lado Norte-Noreste fue construido, tanto para elevar el nivel de la terraza, como con el aparente propósito de proporcionar una impresión de masividad a quienes llegaran desde el Noreste, por la calzada Palomo. Complementa al muro de contención un sistema periférico de "calles" o calzadas empedradas que debieron requerir cantidades apreciables de piedras, así como mano de obra y tiempo para construirlas.

Hay en este conjunto algunos elementos constructivos adicionales. El acceso al mismo, desde la calzada y plazoleta Palomo es mediante una rampa, la cual está flanqueada por dos pozos artesianos de poco más de 1 metro de diámetro y de profundidad. Aparentemente, estos pozos no solamente habrían tenido la función de alentar el drenaje del agua que se acumula en la terraza, sino que pudieron tratarse de obras de captación y almacenamiento de agua, incluso ornato. Sin embargo, se ha observado que constituyen excelentes medios para visualizar las fluctuaciones del nivel freático en el área de la terraza.

Esta última función aparente, permite inferir que la terraza de este conjunto arquitectónico fue construida no sólo con la finalidad de nivelar el terreno, sino principalmente para alejar del nivel freático, tanto la superficie de la terraza como los basamentos habitacionales que se construyeron encima de ella, y sus residentes. Conjugando todos los indicios aquí discutidos, surge la noción de que el exceso de agua y humedad debieron ser una seria preocupación para los constructores y habitantes de este sector del sitio. Agréguese a esto que es únicamente en este sector en donde se 
ha notado en las calzadas, entre algunos de los basamentos, la presencia de acequias cuya finalidad no pudo ser otra que ayudar al drenaje de las aguas de la escorrentía.

La complejidad y sofisticación constructiva reveladas por las obras descritas, contrasta sorpresivamente con la evidente modestia y dimensión restringida de los basamentos circulares que se observan en el conjunto arquitectónico 4. Todos estos se limitan a una o dos hiladas de piedras, de manera que no representan mayores volúmenes de obra civil. Esta peculiar condición del sector residencial del NW resulta todavía más notoria cuando se compara con el impresionante tamaño y volumen de los montículos del Sector Central. La tabla siguiente, ofrece datos acerca del volumen de obra civil de algunas de las estructuras más notorias de los conjuntos arquitectónicos 3 y 4, destacando una relación de 30:1 en los valores promedio calculados.

Volumen comparado de algunas obras civiles del M. N. Guayabo

\begin{tabular}{|c|c|c|c|}
\hline \multirow{2}{*}{$\begin{array}{c}\text { Conjunto } \\
\text { Arquitectónico }\end{array}$} & \multirow[b]{2}{*}{ Estructuras } & \multicolumn{2}{|c|}{ Volumen de Obra Civil $\left(\mathrm{m}^{3}\right)$} \\
\hline & & Por Estructura & $\begin{array}{l}\text { Promedio } \\
\text { Conjunto }\end{array}$ \\
\hline \multirow{3}{*}{ CA-3: Sector Central } & M-1 & 2,169 & \multirow{3}{*}{$1,566.0$} \\
\hline & M-28 & 2,252 & \\
\hline & M-8 & 277 & \\
\hline \multirow{4}{*}{ CA-4: Sector NW } & M-20 & 45 & \multirow{4}{*}{53.5} \\
\hline & M-21 & 71 & \\
\hline & M-22 & 45 & \\
\hline & M-23 & 53 & \\
\hline
\end{tabular}

Aplicando aquí el modelo de la cuadrilla de cuatro trabajadores dedicados a la extracción y acarreo de las piedras para construir alguna de las estructuras del Conjunto Arquitectónico 4, digamos el Montículo-21, el cual se estima que requirió 942 piedras, se habrían requerido 59 días para completar la tarea. Dos cuadrillas, lo habrían hecho en 30 días; y cuatro cuadrillas (16 trabajadores), en 15 días. Ante los resultados de estas estimaciones, debiera estar muy claro que los caciques residentes del sector NW del sitio Guayabo no contaban con la misma capacidad, por ende poder, que sus predecesores del Sector Central. No pudieron convocar ni obtener cantidades comparables de mano de obra constructiva; o de disponer del mismo tiempo suficiente como para extender la tarea por un extenso proceso en etapas. La corrección de esta proposición estaría confirmada, precisamente, por la dimensión restringida de la estructura resultante. 


\section{Conjunto Arquitectónico 5: Plaza y calzada Palomo, obras hidráulicas}

Figura 9

Plazoleta, tanque de sedimentación, puente y estructuras flanqueando la calzada Palomo.

\section{La viñeta ilustra el sector en mayor extensión}
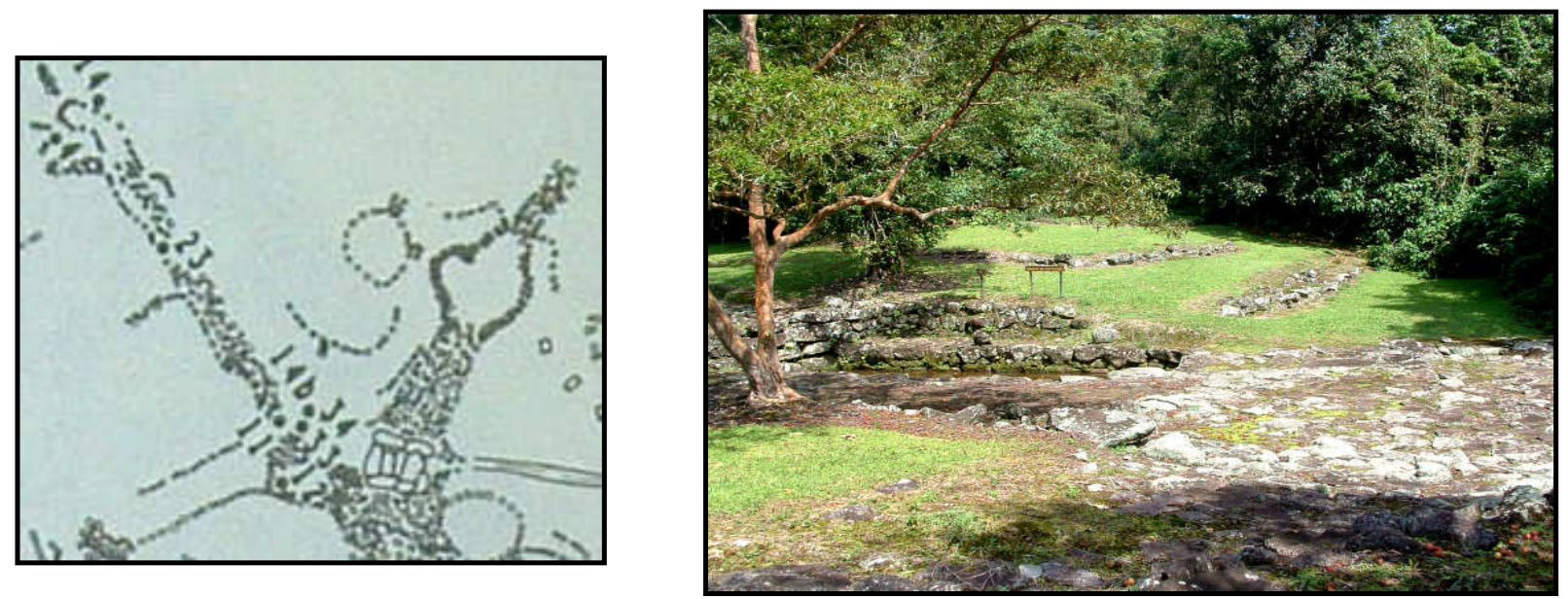

Este conjunto arquitectónico se distribuye por el sector extremo del Noroeste. Comparte calles empedradas con el conjunto anterior, así como la plazoleta Palomo, pero es muy notoria la relación estructural de este sector con la calzada Palomo y con el sistema hidráulico mejor elaborado del sitio, el cual incluye el tanque principal de sedimentación, acueductos subterráneos y el puente en el cual empieza la calzada Palomo.

El Conjunto Arquitectónico 5 incluye dos áreas separadas por la calzada Palomo. Estas áreas comparten la característica de estar delimitadas por notorios muros de contención que definen sendas terrazas. Encima de éstas, aparecen cuatro basamentos y dos tumbas que destacan por su construcción refinada. Dos de estos basamentos circulares, uno en cada terraza, son más grandes que cualquiera de los observados en el Conjunto Arquitectónico 4, pero ninguno logra replicar la magnitud del Sector Central. Cada terraza tiene un basamento grande acompañado de otro de menores dimensiones. Las estructuras de la terraza ubicada por el flanco Este de la calzada Palomo son comparativamente más grandes que las de la otra terraza en el flanco Oeste.

La tabla de datos siguiente, ofrece algunos datos que permiten comparar los dos pares de estructuras descritas, resaltando claramente la mayor magnitud de los montículos de la terraza Este.

Requerimientos de piedra y volúmenes de montículos en el extremo NW

\begin{tabular}{|c|c|c|c|c|}
\hline \multirow{2}{*}{ Terrazas } & Montículos & Cantidad Piedras & Peso Piedras (TM) & $\begin{array}{c}\text { Volumen de } \\
\text { Obra Civil }\left(\mathbf{m}^{3}\right)\end{array}$ \\
\hline \multirow{2}{*}{ Terraza Este } & M-9 & 4,400 & 309.8 & 615.8 \\
\cline { 2 - 5 } & M-10 & 1,885 & 132.7 & 113.1 \\
\hline \multirow{2}{*}{ Terraza Oeste } & M-12 & 1,006 & 70.8 & 80.4 \\
\cline { 2 - 5 } & M-13 & 1,570 & 110.5 & 196.4 \\
\hline
\end{tabular}


Una vez mas, apliquemos el modelo de la cuadrilla de cuatro trabajadores, dedicada a tiempo completo, en jornadas de ocho horas diarias. Para extraer y acarrear la piedra necesaria para la construcción del montículo M-9 se tendrían que haber invertido 275 días, equivalentes a 1,100 días/persona de fuerza de trabajo. Con dos cuadrillas se podría hacer el trabajo en 138 días; con cuatro cuadrillas en 69 días; y con ocho cuadrillas (32 trabajadores), en poco más de un mes.

Comparativamente, el montículo M-13, el más grande de la terraza Oeste, habría requerido los servicios de la cuadrilla de cuatro trabajadores, durante 98 días, equivalentes a 392 días-personas de fuerza laboral. Con dos cuadrillas, la tarea se habría completado en 49 días; y con cuatro cuadrillas, en 25 días. En otras palabras, se puede sugerir que el poder del cacique que ocupó la terraza Este fue 2.8 veces mayor que la de su congénere residente de la terraza Oeste.

Vale la pena agregar que, si aceptamos la noción de que el Montículo Principal (M-1) es el resultado de cuatro etapas constructivas, tal vez puestas a ejecutar por caciques sucesivos de alguna dinastía, entonces el poder y la capacidad de lograr obra civil, representada por el montículo M-9, compara en términos de relativa equivalencia con la primera etapa del M-1. La mayor cercanía de la terraza Este al Sector Central y la presencia de tumbas fastuosas en la misma terraza, contribuyen a la deducción de que subsistía en ésta un nivel de rango muy importante.

\section{Evolución del poder en Guayabo}

Para culminar el presente análisis, hemos considerado adecuado asignar una perspectiva diacrónica al proceso evolutivo del poder en Guayabo, según se manifiesta en la transformación del paisaje construido. La desagregación del sitio en cinco conjuntos arquitectónicos, asociado al análisis de la distribución de los complejos cerámicos en el sitio, permiten presentar un escenario de desplazamiento espacial del centro gravitacional de las actividades en el sitio, en una dirección general del Sureste hacia el Noroeste.

Este desplazamiento, en términos generales aparece vinculado al tiempo, con el sector Sureste en los tiempos más tempranos de ocupación; el Sector Central asociado con la etapa de mayor auge y desarrollo constructivo, en tiempos intermedios; y el Sector Noroeste representando la etapa final de ocupación en tiempos tardíos. El cuadro que sigue resume los aspectos fundamentales del modelo sugerido.

\section{Secuencia espacio-temporal de los conjuntos arquitectónicos en el M. N. Guayabo}

\begin{tabular}{|l|l|l|}
\hline \multicolumn{1}{|c|}{ Conjunto Arquitectónico } & \multicolumn{1}{|c|}{ Montículos Circulares } & \multicolumn{1}{|c|}{ Cronología Relativa } \\
\hline CA-1 Calzada Caragra; entrada principal & \multicolumn{1}{|c|}{} & Temprana e Intermedia \\
\hline CA-2 Plaza-1; montículos gemelos & M-31; M-32; M-33; M-34 & Temprana \\
\hline CA-3 Sector Central con Plaza 2 & M-1 (cuatro etapas); M-28; M-8 & Intermedia \\
\hline CA-4 Complejo residencial del NW & M-20; M-21; M-22; M-24 & Tardía \\
\hline $\begin{array}{l}\text { CA-5 Plazoleta y Calzada Palomo; sistema } \\
\text { hidráulico principal; terrazas extremo NW }\end{array}$ & M-9; M-10; M-12; M-13 & Intermedia y Tardía \\
\hline CA-6 Complejo místico SW & & $\begin{array}{l}\text { Temprana, Intermedia y } \\
\text { Tardía }\end{array}$ \\
\hline
\end{tabular}


El gráfico siguiente ilustra la secuencia de una muestra de montículos de los conjuntos arquitectónicos CA-2, CA-3, CA-5 y CA-4, de manera que se haga notorio el cambio de sus dimensiones a través del tiempo.

Figura 10

Secuencia constructiva de montículos según diámetro y altura de las estructuras

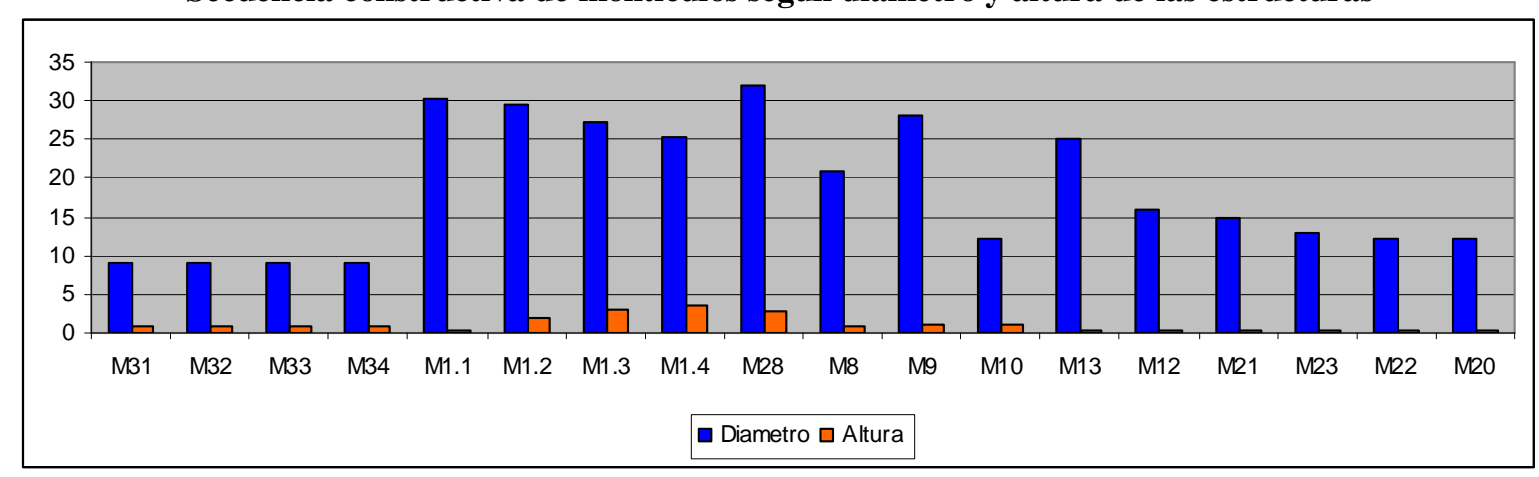

En el caso del Montículo Principal (M-1), las medidas de altura y diámetro han sido desagregadas para presentar los valores que corresponden a los cuatro cuerpos superpuestos que lo componen, sugiriendo etapas constructivas sucesivas y tal vez hasta separadas en el tiempo. Aún así, destaca la dimensión exponencialmente mayor de esta estructura y del montículo M-28, respecto de todas las demás. Cabe mencionar que, en contra de alguna suposición al respecto, los valores del diámetro y la altura de los montículos circulares incluidos en la muestra, no presentan mayor correlación $(r-P e a r s o n=0.48)$.

Para complementar la ilustración del proceso evolutivo del poder en Guayabo, según se refleja en su monumentalidad, el gráfico que sigue conjuga los datos de otras dos variables útiles: 1) el peso estimado de las piedras utilizadas para construir los muros de contención de los montículos; y 2) el volumen resultante de la estructura, en metros cúbicos, incluyendo muros y rellenos. En el caso de estas dos medidas, si se ha encontrado muy alta correlación ( $\mathrm{r}$-Pearson $=0.99$ ).

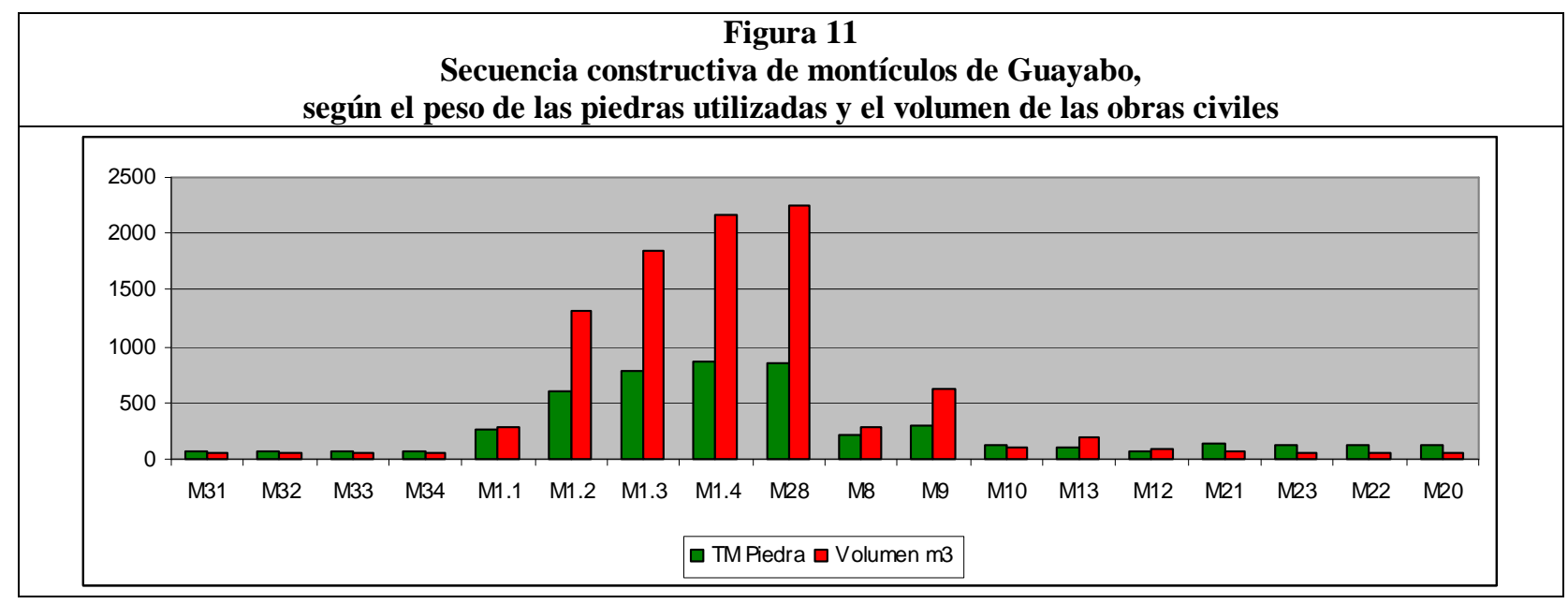


Ambos gráficos ponen de manifiesto que el proceso constructivo en Guayabo, reflejo del poder socio-político de sus residentes, no fue siempre igual, sino que siguió la conocida pauta organicista de un surgimiento modesto inicial, seguido de etapas de crecimiento, florecimiento, apogeo y finalmente decadencia. Los controles cronométricos del sitio Guayabo, indican que este proceso habría sucedido en el lapso del 300 a.C. al 1300 d.C.

\section{Referencias}

Aguilar, C. H. (1972). Guayabo de Turrialba: Arqueología de un sitio indígena prehispánico. San José: Editorial Costa Rica.

Anghera, P. M. (1912). De Orbe Novo: the eight decades of Peter Martyr D'Ánghera. New York: G. P. Putnam's Sons.

Corrales Ulloa, F. \& M. Gutiérrez González. (1986). Williamsburg: evaluación general de un sitio multicomponente del Atlántico Central de Costa Rica. Vínculos, Vol. 12 (Nos. 1-2) pp. 2138. San José: Museo Nacional de Costa Rica.

Chagnon, N. (1973). The culture ecology of shifting (pioneering) cultivation among the Yanomamo indians. En: Peoples and cultures of native South America, New York: D. Gross, editor. Doubleday \& The natural History Press,

Espinosa, G. de. (1864). Relación hecha por Gaspar de Espinosa, Alcalde Mayor de Castilla del Oro. En: Documentos inéditos, J. F. Pacheco et al., compiladores, pp. 467-522, Madrid.

Fernández de Oviedo, G. (1959). Natural History of the West Indias. Chapel Hill: University of North Carolina Press.

Fonseca Zamora, O. (1979). Informe de la primera temporada de re-excavación de Guayabo de Turrialba. Vínculos, Volumen 5 (Nos. 1-2) pp. 35-52. San José: Museo Nacional de Costa Rica.

Fried, Morton H. (1967). The Evolution of Political Society. New York: Random House.

Goldman , I. (1970). Ancient Polynesian Society. University of Chicago Press.

Guerrero, J. V. \& E. Troyo Vargas. (1997). Investigaciones arqueológicas realizadas en el sitio Cutris, Venecia, San Carlos, Costa Rica. San José: Museo Nacional de Costa Rica / Centro de Investigación y Conservación del Patrimonio Cultural, Ministerio de Cultura, Juventud y Deportes.

Gutiérrez González, M., \& L. Hurtado de Mendoza. (1986). Arqueología de Suerre, Costa Central Atlántica, Costa Rica. Vínculos, Volumen 12 (Nos. 1-2) pp. 1-20. San José: Museo Nacional de Costa Rica. 
Gutiérrez González, M., \& G. Mora Sierra. (1988). Reconocimiento y evaluación exploratoria de un complejo arquitectónico localizado entre llanuras: Cubujuquí. Vínculos, Volumen 14 (Nos. 12) pp. 105-119. San José: Museo Nacional de Costa Rica.

Hartman, C. V. (1901). Archaeological researches in Costa Rica. The Royal Ethnographical Museum, Stockholm.

Helms, Mary W. (1979). Ancient Panama: chiefs in search of power. Austin and London: University of Texas Press.

Herrera, A. (2000). Sarapiquí: excavaciones, restauración y divulgación. Informe Final I Etapa de Investigación, Sarapiquí, Alajuela: Proyecto Arqueológico Sarapiquí en el Proyecto Hidroeléctrico Cariblanco.

Hurtado de Mendoza, L. (1986). Gira a la Reserva Indígena Tayní-Telire: Prospección 14. Proyecto de Planificación de la Reserva de la Biosfera La Amistad. Informe de Campo, Servicio de Parques Nacionales (SPN) y Centro Agronómico Tropical de Investigación y Enseñanza (CATIE), Turrialba.

----- (1988). Estratificación social en un cacicazgo de Costa Rica: una aplicación de la inferencia como método de conocimiento en arqueología. En: Hacia una Arqueología Social. Actas del Primer Simposio de la Fundación de Arqueología del Caribe, pp. 46-77, O. Fonseca, editor. Editorial de la Universidad de Costa Rica.

-----. (2002). Desarrollo socioeconómico de la región de Guayabo de Turrialba (tiempos prehispánicos). En: Guayabo de Turrialba, una aldea prehispánica compleja, E. Troyo V., editora, pp. 25-58. San José: Centro de Investigación y Conservación del Patrimonio Cultural, Ministerio de Cultura, Juventud y Deportes.

-----. (2002a). El Sitio Williamsburg, Costa Atlántica de Costa Rica (Reconstruyendo su Historia Ocupacional). En: Manejo de Recursos Culturales, un enfoque arqueológico, L. Hurtado de Mendoza, Capítulo 13, pp. 76-83. San José: Sociedad \& Ambiente Consultores.

-----. (2004). Guayabo: historia antigua de Turrialba. San José: Litografía e Imprenta LIL.

----. (2005). Arqueología en el Proyecto Hidroeléctrico Cariblanco. Área de Gestión Ambiental, Proyecto Hidroeléctrico Cariblanco, Instituto Costarricense de Electricidad (ICE), Colonia Toro Amarillo, Alajuela.

-----. (2005a). Notas de una visita al Sitio El Escobal del Hekwi. Área de Gestión Ambiental, Proyecto Hidroeléctrico Cariblanco (ICE), Colonia Toro Amarillo, Alajuela.

Hurtado de Mendoza, L. \& G. Alvarado Induni. (1988). Datos Arqueológicos y Vulcanológicos de la Región del Volcán Miravalles, Costa Rica. Vínculos, Vol. 14(1988):77-90, San José: Revista del Museo Nacional de Costa Rica. 
Hurtado de Mendoza, L. \& A. C. Arias. (1983). Cerámica y patrones de asentamiento en la región de Guayabo de Turrialba. En: Prehistoric Settlement Patterns in Costa Rica, F. W. Lange \& L. Norr, editores. Journal of the Steward Anthropological Society, Vol. 14 (Nos. 1-2), pp. 281310.

Hurtado de Mendoza, L. y J. Gómez F. (1985). Breve descripción comparativa de dos regiones arqueológicas en Costa Rica: Guayabo de Turrialba y Ta'Lari de Pacuare. Vínculos, Vol. 11:67100. San José: Museo Nacional de Costa Rica.

Ibarra Rojas, E. (1984). Los cacicazgos indígenas de la Vertiente Atlántica y Valle Central de Costa Rica: un intento de reconstrucción etnohistórica. Tesis de Licenciatura, Escuela de Antropología y Sociología, Universidad de Costa Rica, San José.

Kennedy, W. J. (1968). Archaeological investigations in the Reventazón river drainage area, Costa Rica. Ph. D. Dissertation, Tulane University.

Lothrop, S. K. (1926). Pottery of Costa Rica and Nicaragua. New York: Heye Foundation, Museum of the American Indian. También, en español, Managua: Fondo Cultural Banco de América, 1979.

-----. (1937). Coclé, an archaeological study of Central Panama. Part I, Memoirs, Peabody Museum of Archaeology and Ethnology, Vol. 7, Harvard University, Cambridge.

Meléndez, C. (1978). Costa Rica: tierra y poblamiento en la Colonia. San José: Editorial Costa Rica.

Oviedo.(1853). Ver: Fernández de Oviedo (1853).

Sahlins, Marshall D. (1958). Social Stratification in Polynesia. Seattle: University of Washington Press.

Service, E. R. (1971). Primitive Social Organization. New York: Random House.

Snarskis, M. J. (1978). The Archaeology of the Central Atlantic Watershed of Costa Rica. Ph. D. Dissertation, Columbia University.

-----. (1984). Central America: The Lower Caribbean. En: The Archaeology of Lower Central America. F. Lange y D. Stone, editores, Capítulo 8, pp. 195-232, Albuquerque: University of New Mexico Press.

----. (1987). The archaeological evidence for chiefdoms in Eastern and Central Costa Rica. In: Chiefdoms in the Americas, R. D. Drennan \& C. Uribe, Eds., pp. 105-117. University Press of America, Lanham, MD. 
Steward, J. H., ed. (1949). Handbook of South American Indians. Bureau of American Ethnology Bulletin 143, Washington, D.C.: Smithsonian Institution,

Stirling, M. S. (1969). Archaeological investigations in Costa Rica. National Geographic Society Research Reports, 1964 Projects, pp. 239-247, Washington, D.C.

Stirling, M. S. \& M. Stirling Pugh. (1997). Investigaciones arqueológicas en Costa Rica. San José: Museo Nacional de Costa Rica.

Troyo Vargas, E. \& J. E. Garnier Zamora. (2002). Acciones para la preservación del sitio Guayabo: consolidación y restauración. En: Guayabo de Turrialba, una aldea prehispánica compleja. E. Troyo Vargas, editora, pp. 71-136. San José: Ministerio de Cultura, Juventud y Deportes.

Valerio Lobo, W., Solís Alpízar, O. \& F. Solís del Vecchio. (1986). Agua Caliente de Cartago: del rescate súbito a la investigación a largo plazo. Vínculos, Volumen 12 (Nos. 1-2), pp. 39-50. San José: Museo Nacional de Costa Rica.

Vázquez L. R., ed. (2002). Arqueología del Área de Influencia del Proyecto Hidroeléctrico Angostura, Valle de Turrialba. San José: Instituto Costarricense de Electricidad y Museo Nacional de Costa Rica.

Vázquez, R., Massey; H. \& J. C. Sánchez. (2002). Guayabo y su relación con el Valle de Turrialba en el Período VI (1000-450 a.C.): Prospección de las Calzadas Caragra y Alto Varas. En: Arqueología del Área de Influencia del Proyecto Hidroeléctrico Angostura, Valle de Turrialba. R. Vázquez, editor, Capítulo 13. San José: Instituto Costarricense de Electricidad y Museo Nacional de Costa Rica.

Wafer, L. (1934). A new voyage and description of the Isthmus of America. Cleveland: Burrows Brothers Co.

Young, P. D. (1971). Ngawbe: tradition and change among the Western Guaymí of Panama. Illinois Studies in Anthropology, $\mathrm{N}^{\mathrm{o}} 7$. 